NISTIR 7958

\title{
Persistent Organic Pollutants and Vitamins in Northern Fur Seals (Callorhinus ursinus) Collected from St. Paul Island, Alaska as Part of the Alaska Marine Mammal Tissue Archival Project
}

John Kucklick, Jessica Reiner, Michele Schantz, Jennifer Keller, Jennifer Hoguet, Catherine Rimmer, Tamika Ragland, Rebecca Pugh, Amanda Moors, Jody Rhoderick, Jennifer Ness, Danielle Peterson, Paul Becker 
NISTIR 7958

\section{Persistent Organic Pollutants and Vitamins in Northern Fur Seals (Callorhinus ursinus) Collected from St. Paul Island, Alaska as Part of the Alaska Marine Mammal Tissue Archival Project}

John Kucklick, Jessica Reiner, Michele Schantz, Jennifer Keller, Jennifer Hoguet, Catherine Rimmer, Tamika Ragland, Rebecca Pugh, Amanda Moors, Jody Rhoderick, Jennifer Ness, Danielle Peterson, Paul Becker

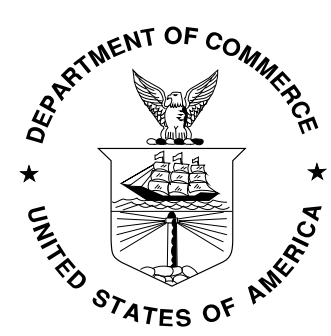

U.S. Department of Commerce Rebecca Blank, Acting Secretary

National Institute of Standards and Technology 


\section{ABSTRACT}

Liver and blubber samples from 50 juvenile male northern fur seals (Callorhinus ursinus) were collected on St. Paul Island from four different seal rookeries between 1987 and 2007. Samples were analyzed for vitamins and for both legacy and current-use persistent organic pollutants (POPs). The resultant data set provides information on how concentrations of the two groups of POPs are changing with time in the northern fur seal population. Legacy POPs determined included polychlorinated biphenyl congeners (PCBs), dichlorodiphenyltrichloroethane (DDT) and metabolites, chlorobenzenes, toxaphene, chlordane-related compounds, and mirex. With the exception of mirex, all legacy compounds showed statistically significant declines with sampling year consistent with trends observed in marine mammals from other northern areas such as the Canadian Arctic. Overall, concentrations of legacy POPs are similar to levels seen in seal samples from other areas of the North Pacific Ocean and the Bering Sea and are considerably lower (factor of 10 or greater) than observed in marine mammals from temperate regions of the United States. The current-use brominated flame retardants, polybrominated diphenyl ether (PBDE) and hexabromocyclododecane (HBCD), showed exponential increases with sampling year although PBDE concentrations may be reaching a plateau. Likewise, perfluorinated alkyl acids (PFAAs) also show exponential increases with sampling year indicating continued release and incorporation into the North Pacific food web. Concentrations of retinol and $\alpha$ - and $\gamma$-tocopherol (vitamin E) in liver were not related to POP concentrations, year of sampling, or the rookery where the seal sample originated. POP concentrations do not appear to influence vitamin concentrations as observed in other wildlife studies. Further monitoring of northern fur seals is warranted because of increasing concentrations of current-use POPs and declining northern fur seal populations.

\section{Introduction}

The monitoring of marine mammals from northern regions for temporal and spatial changes in persistent organic pollutant (POP) concentrations has provided important information often driving regulatory action on chemical production and use. For instance, the detection of temporal increases in polybrominated diphenyl ethers (PBDEs) in ringed seals and the initial detection of perfluorooctane sulfonate (PFOS) in polar bears in Canada helped fuel the eventual phasing-out of these chemicals in North America (Ikonomou et al., 2002; Kannan et al., 2001). Recent monitoring of marine mammals from Arctic and sub-Arctic regions have identified new compounds, such as the flame retardant hexabromocyclododecane (HBCD), that are in current use and are being considered for phase-out (de Wit et al., 2010). 
Detecting time trends of POPs in marine mammals requires samples collected at multiple time points, generally over several decades, and stored in proper conditions. To address this need, specimen banks were established in several countries including the US, Canada, Denmark, Scandinavia, and Japan to collect and archive marine mammal tissues in order to detect pollutant temporal trends (Becker et al., 2006). In the US, the National Institute of Standards and Technology (NIST) maintains the Marine Environmental Specimen Bank (Marine ESB) consisting of several different marine mammal tissue collections (Becker and Wise, 2006). One of these collections, the Alaska Marine Mammal Tissue Archival Project (AMMTAP), is ideal for assessing temporal changes of POPs in marine mammal populations. The AMMTAP collection spans from 1987 to the present day and contains liver, kidney and blubber samples obtained only from freshly dead animals using sampling protocols designed to reduce the likelihood of accidental sample contamination. Samples are processed in the field and then shipped to the NIST Marine ESB at liquid nitrogen vapor-phase temperatures $\left(-150{ }^{\circ} \mathrm{C}\right)$ prior to permanent storage in liquid nitrogen vapor-phase freezers located in a clean room facility. The AMMTAP collection presently contains over 5,000 samples from 710 animals from 18 species of cetaceans, pinnipeds, and fissipeds collected from a variety of maritime regions in Alaska.

The objective of the present work was to use samples from the AMMTAP collection to assess temporal trends of POPs in northern fur seals (Callorhinus ursinus) occurring at summer rookeries in the Bering Sea (Table 1; Figure 1). Temporal trend data for both legacy persistent organic pollutants (legacy POPs), such as polychlorinated biphenyls (PCBs), and current or recently used POPs, such as the polybrominated diphenyl ethers (PBDEs), are needed from this region. Such data would provide a better understanding of POP concentrations trends in species from northern climates in response to climate change and source reductions mandated in the Stockholm Convention or other management activities (Riget et al., 2010). Fur seals are also consumed as food at the St. Paul Island collection site; therefore, understanding human exposure to current-use and legacy POPs was therefore also a motivation for this project. Vitamins were determined in samples as vitamin levels have been linked to POP concentrations in other work.

\section{The Northern Fur Seal}

The northern fur seal (NFS) is an otariid (externally eared) seal that has a wide geographic range in the North Pacific Ocean extending from Japan and Northern California northward to the Bering Sea (Gentry, 1997). The NFS tends to be smaller than most other species of otariid seals and weighs up of $250 \mathrm{~kg}$. Adults are sexually dimorphic with mature males being much larger than females. The seals are polygynous and have established large breeding colonies (rookeries) at several locations in the Bering Sea, including at St. Paul in the Pribilof Islands (Fig. 
1). Dominant males compete for harems of females while younger males gather in groups on or near their natal beaches. These younger immature males ( 2 to 3 years old) are harvested for food (and historically for pelts) at some locations, such as St. Paul Island. Breeding and pupping occur in the summer with peak pupping occurring typically during the first two weeks of July. Females raise a single pup and forage in local waters between feedings. When not on rookeries, NFSs are pelagic in the northern North Pacific Ocean. Animals using the St. Paul Island rookeries (Fig. 1), mainly subsist on pollock, sand lance, and squid (Antonelis et al., 1997). Pup production on St. Paul Island has declined nearly three-fold since the early 1970s, possibly as a result of declining forage fish availability due to climate change or from competition with commercial fisheries (Towell and Ream, 2006).

\section{Persistent Organic Pollutants}

Persistent organic pollutants can be categorized as either legacy or current-use. Legacy POPs are those that have been banned or phased-out from use in North America or were part of the original "dirty dozen" compounds specified in the Stockholm Convention (see www.pops.int). Legacy POPs include the PCBs, DDTs, chlordanes, toxaphene, hexachlorobenzene (HCB), aldrin, endrin, dieldrin, heptachlor, and mirex that were measured in this study in addition to polychlorinated dioxins and furans that were not determined in this work (Table 1). In 2009 and 2011, $\alpha-$, $\beta$ - and $\gamma$-hexachlorocyclohexane $(\mathrm{HCH})$, pentachlorobenzene, perfluorooctane sulfonate (PFOS), endosulfan, and PBDEs, all measured in this study, were added to the Stockholm Convention POPs list. Chlorodecone (Kepone) and hexabromobiphenyl, which were not measured in the present work, are also on the Stockholm POPs list. Non-legacy POPs include those that still have some limited production or are still in wide-spread use, the perfluoro alkyl acids (PFAAs), PBDEs, and HBCDs fall into this category. In general, levels of these compounds are increasing in Arctic and nearby regions (de Wit et al., 2010; de Wit and Muir, 2010; Hoguet et al., 2013; Reiner et al., 2011).

There has been keen interest in determining both temporal and spatial trends of POPs in the Arctic and nearby environs such as the Bering Sea and North Pacific Ocean to understand concentration trajectories or possible toxic effects in marine food webs. Both of these ocean basins are believed to be major receptors of POP emissions and are proximate to Asia where legacy POPs are either still in use or where use has only recently been curtailed. Consequently, temporal trends of POPs in these regions are of interest. In addition, the accumulation of POPs in marine mammals such as polar bears, dolphins, and seals has been linked to toxic effects including suppressed immune function and endocrine disruption (Beckmen et al., 2003; Lahvis et al., 1995; Letcher et al., 2010). Determining POP concentrations in northern fur seals was therby important to place their contaminant burdens in perspective to burdens in marine 
mammals where levels are linked to toxic effects. From a human health perspective, Native Alaskans frequently rely on marine mammals for subsistence thus placing humans in a similar trophic position as marine mammals. Therefore, understanding human exposure to POPs was an additional motivation for this study.

There have been two prior investigations of POPs in northern fur seals. Beckman et al. (Beckmen et al., 2003) collected blood and milk samples from NFS mother/pup pairs on St. Paul Island and examined the relationship between blood POP concentration and immune response. Primiparous females had higher POP concentrations and mounted weaker immune response following vaccination than multiparous females. The results suggest an effect of higher POP levels in blood leading to decreased immune response in NFS (Beckmen et al., 2003; Beckmen et al., 1999). Temporal trends of POPs in NFS have been reported in blubber from mature female fur seals collected from 1971 through 2008 off of the Sanriku Coast in Japan (Kajiwara et al., 2004). Significant declines were observed for PCBs from 1975 onward. PBDEs accumulation mirrored PBDE usage in Japan during that time span with concentrations increasing until 1994 and then declining in more recent years. HCB did not show significant declines. Aside from this work, there have been no studies documenting temporal trends of POPs in NFSs highlighting the need for the present work.

\section{Materials and Methods}

\section{Samples}

Samples of liver and blubber were collected opportunistically from two to three year old male fur seals after they were taken during subsistence hunts on Saint Paul Island, Alaska (Figure 1 and Table 2). Samples were collected from 50 seals in $1987(n=5), 1990$ ( $n=10), 1997(n=5)$, $2000(n=10), 2006(n=10)$, and $2007(n=10)$. Data on seal weight, length and blubber thickness were only available for samples collected prior to 2000.

Blubber and liver samples were processed in the field using established protocols that were designed to minimize sample contamination (Becker and Wise, 2006). After processing, samples were placed in liquid nitrogen vapor-phase shippers and then sent to the NIST Marine Environmental Specimen Bank (Marine ESB) for storage and later homogenization following established protocols (Pugh et al., 2007). While in the NIST Marine ESB, samples were stored in liquid nitrogen vapor-phase freezers $\left(-150{ }^{\circ} \mathrm{C}\right)$ in a clean room environment. Samples designated for analysis and not long term archival were cryogenically homogenized using the method described elsewhere (Zeisler et al., 1983). 


\section{Vitamins}

\section{Sample Preparation}

QC97LH2, a beluga liver control material, and 49 NFS liver samples were provided by the NIST Marine ESB. Calibration solutions $(n=5)$ were prepared of the fat-soluble vitamins $A$ (retinol) and $E$ ( $\alpha$-tocopherol and $\gamma$-tocopherol, respectively) (all concentrations determined spectrophotometrically). A solution of benzo[a]pyrene- $d_{12}$ in methanol (approximately $7 \mu \mathrm{g} / \mathrm{g}$ ) was prepared and used as the internal standard (IS).

NFS liver samples (approximately $1 \mathrm{~g}$ ) and a liver quality control sample (QC97LH2) (approximately $1 \mathrm{~g}$ ) were gravimetrically weighed into hot block digestion cups. Six milliliters of a 1:1 (volume fraction) tetrahydrofuran/methanol mixture with $200 \mathrm{mg} / \mathrm{g}$ pyrogallol was added to each sample. The samples were allowed to stir for $15 \mathrm{~min}$. After stirring, $1.2 \mathrm{~mL}$ of $50 \%$ (volume fraction) $\mathrm{KOH}$ in methanol was added to the sample. The samples were stirred at $40{ }^{\circ} \mathrm{C}$ for $1 \mathrm{~h}$ followed by the addition of $500 \mu \mathrm{L}$ of acetic acid to neutralize the base and an additional $10 \mathrm{~mL}$ of water containing $10 \% \mathrm{NaCl}$ (mass fraction).

Liquid-liquid extraction was performed three times using $10 \mathrm{~mL}$ of a 1:1 (volume fraction) hexane:petroleum ether mixture. The combined extract was evaporated to approximately 20 $\mathrm{mL}$ and washed with water. The organic layer was removed, evaporated to dryness, and then reconstituted in $1 \mathrm{~mL}$ of 9:1 (volume fraction) ethanol:ethyl acetate. All of the above steps were performed in a room with subdued lighting, and when possible, the samples were fully shielded from the light.

\section{Instrumental method}

Analysis was performed on an Agilent 1100 liquid chromatograph (LC) coupled with a Dionex UltiMate 3000 LC/UV with a Jasco FP-1520 fluorescence detector. Samples (20 $\mu$ L) were injected onto a Hypersil Green PAH column ( $250 \mathrm{~mm} \times 4.6 \mathrm{~mm}$ i.d., $5 \mu \mathrm{m}$ particles) held at $5{ }^{\circ} \mathrm{C}$. An isocratic mobile phase consisting of $97 \%$ acetonitrile with $3 \%$ methanol by volume for 50 min was used for the separation. A response factor was calculated for each calibrant injection, and the average response factor was used for the calculation of retinol and tocopherol concentrations in the liver samples. 
PCB Congeners, DDT compounds, Mirex, Chlorinated Cyclodienes, HCHs, PBDE Congeners, $H C B$, and $H B C D s$

\section{Sample Preparation}

Calibrants were prepared by gravimetrically combining the following solutions: Standard Reference Materials (SRMs) 2261, 2262, 2274, 2275, two additional PCB congener solutions, a solution of 26 PBDE congeners, a solution of PBDE 209, commercially purchased solutions of octachlorosytrene (Accustandard, Inc., New Haven, CT), three isomers of HBCDs, and toxaphene congeners Parlar 26, 32, 50 and 62 (Cambridge Isotope Laboratories, Andover, MA). Concentrations of components in the non-SRM solutions used to prepare the calibrants were not corrected for purity although the stated purities were all $>98 \%$. The six-point calibration curve, processed alongside each sample set, contained from approximately $0.05 \mathrm{ng}$ to $230 \mathrm{ng}$ of each component of interest.

An internal standard (IS) solution in iso-octane contained the following compounds obtained from Wellington Laboratories (Guelph, Ontario, Canada), Cambridge Isotope Laboratories, Accustandard, and Chiron (Trondheim, Norway): ${ }^{13}$ C-labeled PCB congeners $(28,52,77,126$, 169, 118, 153, 180, 194, and 206), 6-F-PBDE 47, PBDE 104, 4'-F-PBDE 160, 4'-F-PBDE 208, ${ }^{13}$ Clabeled PBDE 209, ${ }^{13} \mathrm{C}$-labeled pesticides (HCB, trans-chlordane, trans-nonachlor, oxychlordane, 4,4'-DDE, 4,4'-DDD, 4,4'-DDT), ${ }^{13} \mathrm{C}$-labeled methyl-triclosan and ${ }^{13} \mathrm{C}$-labeled $\alpha-$-, $\beta$ - and $\gamma$-HBCDs. This solution contained approximately $300 \mathrm{ng} / \mathrm{g}$ (mass fraction) of each compound.

Blubber samples ( $\sim \mathrm{g}$ ) including subsamples of SRM 1945 Organics in Whale Blubber as a control sample were extracted using pressurized fluid extraction (PFE; ASE Dionex, Sunnyvale, CA). Thee samples, FRSL-187, 808, and 828, were run in duplicate with one analysis in each of two batches. Cryohomogenized blubber was mixed with diatomaceous earth (Hydromatrix, Restek, Bellefonte, PA) or sodium sulfate and then packed into stainless steel extraction vessels. The IS solution was gravimetrically added to the top of each PFE vessel. The mixtures were extracted using dichloromethane. The cell temperature and pressure were set to $100{ }^{\circ} \mathrm{C}$ and 13.8 MPa, respectively, and there were three extraction cycles. Extracts were frozen, and the residual water was removed. Total extractable organic content (or lipid content) was determined gravimetrically by subsampling the extract. Solvent volume was reduced to $1 \mathrm{~mL}$ under nitrogen and lipid was removed by size exclusion chromatography column (PLGel $10 \mu \mathrm{m}$, $100 \AA$ A). The resultant fraction was evaporated to $0.5 \mathrm{~mL}$ and solvent exchanged to hexane. An additional step was performed using solid phase extraction cartridges packed with $30 \%$ sulfuric acid/silica (mass fraction) in order to further clean up the samples and fractionate the more polar HBCD isomers from the other analytes as described previously (Hoguet et al., 2013). Fraction One (F1) extracts were solvent exchanged to iso-octane, evaporated, and transferred to amber auto sampler vials with a final volume of $0.5 \mathrm{~mL}$. Fraction Two (F2) extracts 
containing $\mathrm{HBCD}$ isomers were solvent exchanged to iso-octane then methanol, evaporated, and transferred to auto sampler vial (ASV) inserts and reduced to a final volume of approximately $200 \mu \mathrm{L}$. FI extracts were analyzed using gas chromatography with mass spectrometric detection (GC/MS) for the majority of the compounds using two ionization modes as described below, and F2 extracts were analyzed using liquid chromatography with a triple quadrupole MS (LC-MS/MS) for HBCDs.

\section{Instrumental method}

\section{GC/MS-EI for PCB Congeners, DDT-related compounds, and Mirex}

Samples were analyzed using two GC/MS injections, one for the pesticides and one for the PCB congeners. Both were on an Agilent 6890N GC coupled to an Agilent 5973 MS (Agilent Technologies, Santa Clara, CA) operated in the electron impact (EI) mode with selected ion monitoring (SIM). The column used for the first injection was a DB-XLB $(0.25 \mathrm{~mm} \times 60 \mathrm{~m} \times 0.25$ $\mu \mathrm{m}$; Agilent Technologies) coupled to a $5 \mathrm{~m} \times 0.25 \mathrm{~mm}$ retention gap. Cool-on-column injections of $1 \mu \mathrm{L}$ were done for the pesticide run. The column temperature for the pesticide run was held for $1 \mathrm{~min}$ at $60^{\circ} \mathrm{C}$, ramped to $180^{\circ} \mathrm{C}$ at a rate of $40{ }^{\circ} \mathrm{C} / \mathrm{min}$, held for $10 \mathrm{~min}$ at 180 ${ }^{\circ} \mathrm{C}$, then ramped to $280^{\circ} \mathrm{C}$ at a rate of $2{ }^{\circ} \mathrm{C} / \mathrm{min}$, and finally held at $280^{\circ} \mathrm{C}$ for $5 \mathrm{~min}$.

The second run, for PCB congeners, utilized the same column as the first injection. Cool-oncolumn injections of $1 \mu \mathrm{L}$ were done for the PCB run. The column temperature for the PCB run was held for $1 \mathrm{~min}$ at $60^{\circ} \mathrm{C}$, ramped to $180^{\circ} \mathrm{C}$ at a rate of $40{ }^{\circ} \mathrm{C} / \mathrm{min}$, held for $10 \mathrm{~min}$ at $180^{\circ} \mathrm{C}$, then ramped to $280^{\circ} \mathrm{C}$ at a rate of $2{ }^{\circ} \mathrm{C} / \mathrm{min}$, and finally held at $280^{\circ} \mathrm{C}$ for $46 \mathrm{~min}$.

\section{GC/MS-NCI for PBDEs, Cyclodienes, HCHs and Chlorobenzenes}

The PBDEs, cyclodienes, $\mathrm{HCHs}$, and chlorobenzenes were analyzed using an Agilent $6890 \mathrm{GC}$ and 5975B MS (Agilent Technologies) operated in the negative chemical ionization $(\mathrm{NCl})$ mode with SIM. Methane was used as the reagent gas. The column used was a $30 \mathrm{~m} \times 0.18 \mathrm{~mm} \times 0.18 \mu \mathrm{m}$ DB-5ms (Agilent Technologies) equipped with a $5 \mathrm{~m} \times 0.25 \mathrm{~mm}$ retention gap. Sample extracts (reduced to $0.5 \mathrm{~mL}$ ) were injected $(2 \mu \mathrm{L})$ using cool on-column injection. The column temperature for the $\mathrm{NCl}$ run was held for $1 \mathrm{~min}$ at $60{ }^{\circ} \mathrm{C}$, ramped to $170{ }^{\circ} \mathrm{C}$ at a rate of 25 ${ }^{\circ} \mathrm{C} / \mathrm{min}$, then ramped to $270{ }^{\circ} \mathrm{C}$ at a rate of $2{ }^{\circ} \mathrm{C} / \mathrm{min}$, next ramped to $325{ }^{\circ} \mathrm{C}$ at a rate of 25 ${ }^{\circ} \mathrm{C} / \mathrm{min}$, and finally held at $325^{\circ} \mathrm{C}$ for $15 \mathrm{~min}$. 


\section{LC-MS/MS for HBCDs}

LC-MS/MS was used with the electrospray ionization (ESI) source. A $20 \mu \mathrm{L}$ injection of F2 extracts was made, and HBCD isomers were separated on an Agilent Eclipse Plus C18 column ( $3.0 \mathrm{~mm} \times 150 \mathrm{~mm} \times 3.5 \mu \mathrm{m}$ column) connected to an API 4000 (Applied Biosystems, Foster City, CA). The solvent program was as follows: solvent $A$ was $2.5 \mathrm{mM}$ ammonium acetate in $12.5 \%$ water in methanol (volume fraction) and solvent B was acetonitrile. Flow was 0.3 $\mathrm{mL} / \mathrm{min}$ and the following mobile phase gradient was used. Initial conditions began at $90 \% \mathrm{~A}$, ramped to $67 \% \mathrm{~A}$ by $12 \mathrm{~min}$, and held at $67 \% \mathrm{~A}$ for $3 \mathrm{~min}$. At $15 \mathrm{~min}$, the solvent was ramped to $0 \% \mathrm{~A}$ by $20 \mathrm{~min}$, held for $3 \mathrm{~min}$, and then ramped from $23 \mathrm{~min}$ to $28 \mathrm{~min}$ to $90 \% \mathrm{~A}$ and held for $5 \mathrm{~min}$.

\section{Perfluorinated Alkyl Acids}

\section{Sample Preparation}

One aliquot of NIST SRM 1946 Lake Superior Fish Tissue and one aliquot of SRM 1947 Lake Michigan Fish Tissue were run as control materials in this analysis and compared to concentrations determined previously (Reiner et al., 2012). A calibration series $(n=7)$ was prepared from three independent weighings of neat PFAAs in methanol (see Table 3 for list). A solution of ${ }^{13} \mathrm{C}_{8}$-PFOA, ${ }^{13} \mathrm{C}_{9}$-PFNA, ${ }^{13} \mathrm{C}_{9}$-PFDA, ${ }^{13} \mathrm{C}_{2}$-PFUnA, ${ }^{13} \mathrm{C}_{2}$-PFDoA, ${ }^{18} \mathrm{O}_{2}$-PFBS, ${ }^{13} \mathrm{C}_{4}$-PFOS, and ${ }^{18} \mathrm{O}_{2}$-PFOSA in the water was used as the IS solution for PFAAs. A methanolic solution of ${ }^{13} \mathrm{C}_{2^{-}}$ PFOA was used as the recovery standard.

Samples and calibrants were extracted using the potassium hydroxide $(\mathrm{KOH})$ in methanol method as described previously (Reiner et al., 2011). Briefly, approximately $0.5 \mathrm{~g}$ of each sample was transferred to a $50 \mathrm{~mL}$ polypropylene centrifuge tube using a stainless steel spatula. MilliQ water $(0.5 \mathrm{~mL})$ was added to each sample. The aqueous IS $(0.2 \mathrm{~mL})$ was then gravimetrically added to each sample. The centrifuge tubes were vortexed for $10 \mathrm{sec}$ and allowed to settle for $20 \mathrm{~min}$. Three milliliters of $0.01 \mathrm{~mol} / \mathrm{L} \mathrm{of} \mathrm{KOH}$ in methanol was added to the samples and sonicated for $30 \mathrm{~min}$. Samples were then centrifuged at $2500 \mathrm{rpm}$ for $5 \mathrm{~min}$, and the supernatant was transferred to a glass culture tube with a glass pipet. The original sample tube received an additional $3 \mathrm{~mL}$ of $0.01 \mathrm{~mol} / \mathrm{L}$ of $\mathrm{KOH}$ in methanol, and the extraction procedure was repeated, placing the additional round of supernatant in the glass culture tube as well. Extracts were evaporated under nitrogen, at $35{ }^{\circ} \mathrm{C}$, to approximately $3 \mathrm{~mL}$ and filtered using a Whatman UniPrep $0.2 \mu \mathrm{m}$ filter (Stanford, ME). Samples were further evaporated to 1 $\mathrm{mL}$ (under nitrogen) and $10 \mathrm{~mL}$ of $50 \%$ (volume fraction) formic acid (98\%, Fluka; Buchs, Switzerland) in water was added to each sample. Samples were loaded onto Waters Oasis WAX 
SPE columns (3 cc, 60 mg, $30 \mu \mathrm{m}$; Milford, MA) on a RapidTrace (Biotage, Uppsala, Sweden) workstation. The fraction of interest from the SPE column was concentrated under nitrogen to approximately $0.5 \mathrm{~mL}$. They were spiked with $0.2 \mathrm{~mL}$ of the recovery standard, vortexed, and transferred to ASVs for instrumental analysis.

\section{Instrumental method}

The extracts were run using the LC-MS/MS (Agilent 1100 LC (Palo Alto, CA) interfaced to a negative electrospray ionization tandem mass spectrometer (API 4000, Applied BiosystemsMDS Sciex, Foster City, CA). Samples $(5 \mu \mathrm{L})$ were injected onto a Phenomenex Kinetex $2.6 \mu$ PFP column ( $50 \mathrm{~mm} \times 3.0 \mathrm{~mm}$ ). The solvent gradient given in \% by volume (flow rate $0.3 \mathrm{~mL} / \mathrm{min}$ ) started at $40 \%$ methanol and $60 \% 20 \mathrm{mmol} / \mathrm{L}$ ammonium acetate in water and then increased to $65 \%$ methanol by $5 \mathrm{~min}$, held for $5 \mathrm{~min}$, and then increased to $95 \%$ methanol by $12 \mathrm{~min}$, and held for $3 \mathrm{~min}$, before reverting back to original conditions at $15.5 \mathrm{~min}$ with a $14.5 \mathrm{~min}$ hold time. The two most abundant transitions for each PFAA were monitored.

\section{Quantification of Analytes of Interest}

Amounts of each compound of interest in the samples were calculated using the slope and $y$ intercept of at least a three point calibration curve that bracketed the peak area ratios observed in the samples. Concentrations were determined by dividing the calculated analyte mass by the extracted sample mass. The limits of detection (LOD) were determined as the maximum value of either the average ng measured in procedural blanks plus 3 times the standard deviation of the blanks or the lowest calibrant detectable, all divided by the sample mass. For the PFAAs, final concentrations are corrected for the salt content of the neat materials, and concentrations are totals including branched and linear isomers.

\section{Statistical methods}

Statistical comparisons were performed using JMP 10 (SAS Institute, Cary, NC). POP concentrations and vitamins were log transformed to provide a normal distribution. Lipid content did not require log transformation. Comparisons were made by performing multiple linear regression including the rookery and year as independent variables. 


\section{Results and Discussion}

\section{Vitamins}

Vitamin levels in free-ranging marine mammals are reflective of many factors (physiological, biological, and chemical). While vitamins $A$ and $E$ are essential for reproduction, development, cellular and immune function, little is known about the "normal" levels in wildlife (Simms and Ross, 2000). This study provides much needed information about the mass fractions of vitamin A (retinol) and vitamin $E$ ( $\alpha$ - and $\gamma$-tocopherol) in one species of marine mammal. Mass fractions of total retinol ( $\sum$ retinol), $\alpha$ - and $\gamma$-tocopherol are shown for the control material in Table 4. The relative standard deviation for retinol and $\gamma$-tocopherol were less than $10 \%$, however the relative standard deviation for $\alpha$-tocopherol was $30 \%$ indicating higher variability in the measurement of this vitamin. Vitamin concentrations in the NFS liver samples are given in Table 5 with means by rookery shown in Table 6 . Mass fractions of the vitamins in livers were highest for $\alpha$-tocopherol with the concentration ranging from below the limit of detection to $23400 \mathrm{mg} / \mathrm{kg}$ in frsl-54 (median $10300 \mathrm{mg} / \mathrm{kg}$ ). Log transformed vitamin mass fractions did not significantly differ among rookeries or year, nor was there a significant statistical interaction between rookery and year. In other words, vitamin concentrations did not differ among rookeries or among sampling years in the seals and mass fraction of vitamins exhibited considerable variability among individual seals. The relative standard deviation of the three vitamins were $134 \%, 43 \%$ and $42 \%$ for $\Sigma$ retinol, $\alpha$ - and $\gamma$-tocopherol, respectively. Since there is no baseline information on the concentrations of $\Sigma$ retinol, $\alpha$ - and $\gamma$-tocopherols in NFS, we can assume that the differences seen in this study is due to feeding/post feeding intervals, seal condition and prey sources. Vitamin concentrations were also not significantly related to summed POP concentrations.

\section{Legacy Organochlorine POPs}

Since lipid content in tissues is often correlated to concentrations of lipophilic (fat-soluble) pollutants such as PCBs and DDTs, lipid content was determined in all NFS blubber samples. Lipid content ranged from $42.9 \%$ (mass fraction) to $84.3 \%$ with an average value of $68.5 \%$ (SD $=9.5 \%$; Table 2). POPs were not correlated to lipid content therefore POP concentrations were not lipid normalized and are expressed on a wet mass basis.

The quality control of sample analysis for the organochlorine POPs included analyzing four aliquots of SRM 1945. Results from the analysis of SRM 1945 are shown in Tables 7 and 8. The mean concentration of the four aliquots was within the uncertainty or within $20 \%$ of the certified values listed on the Certificate of Analysis except for trans-chlordane (Table 7). The 
reason for the higher trans-chlordane value relative to the certified value for SRM 1945 (17.8 $\mathrm{ng} / \mathrm{g}(1.7 \mathrm{ng} / \mathrm{g} \mathrm{SD})$ vs. $11.8 \mathrm{ng} / \mathrm{g} \pm 0.5 \mathrm{ng} / \mathrm{g}$ ) may result from the coelution of trans-chlordane enantiomers in this study that separated during the certification measurements. Toxaphene congeners determined in SRM 1945 were between $88 \%$ and $43 \%$ higher than reference values derived from interlaboratory comparisons and prior analysis of toxaphene congeners by NIST. The discrepancy is likely due to non-agreement of stated concentrations of toxaphene congeners in an earlier lot compared to the lot used for this work. This earlier lot was used by NIST and was likely used by other laboratories that submitted data to NIST during the recertification of SRM 1945. Purity was assessed in the most recently used lots of toxaphene congeners; however concentration values stated by the vendor could not verified. Regardless, the toxaphene values in this study are internally consistent and are useful to gauge the decline of toxaphene concentrations in NFS with time.

The average percent difference of values determined in duplicate measurement on the same homogenized seal blubber ranged from $14 \%$ for pesticides determined by $\mathrm{GC}-\mathrm{MS} / \mathrm{NCl}$ to $2.5 \%$ for PCBs determined by GC-MS/EI.

Concentration values for legacy POPs are given in Tables 9 and 10 and summarized in Tables 11 and 12. Median concentrations of legacy POPs were highest for $\Sigma$ PCBs at $1540 \mathrm{ng} / \mathrm{g}$ (range 558 $\mathrm{ng} / \mathrm{g}$ to $2210 \mathrm{ng} / \mathrm{g}$ ) and lowest for the $\Sigma \mathrm{ClBz}$ at $2.93 \mathrm{ng} / \mathrm{g}$ (range $1.37 \mathrm{ng} / \mathrm{g}$ to $7.54 \mathrm{ng} / \mathrm{g}$ ). $\mathrm{EDDTs}$ concentrations in NFS were highly variable ranging from $223 \mathrm{ng} / \mathrm{g}$ to $83200 \mathrm{ng} / \mathrm{g}$ (Tables 10 and 11). The variability in $\Sigma D D T$ concentrations was partially driven by a significant $(p<0.001)$ decline with year of sampling (Figure 2), but among colony differences in $\Sigma$ DDTs irrespective of year were not significantly different however colonies were not sampled all years (Table 2 and Figure 3). While concentrations generally declined with year of sampling, there was a significant $(P<0.001)$ and nearly 3-fold increase in SDDT concentration from 2006 until 2007 (from $464 \mathrm{ng} / \mathrm{g}(207 \mathrm{ng} / \mathrm{g}$ ) to $1230 \mathrm{ng} / \mathrm{g}(590 \mathrm{ng} / \mathrm{g}$ ) (mean (1SD)). This may be due to differences in forage location that appears to be colony dependent (Call et al., 2008) or possibly differences in dispersal during the non-breeding season. An annual difference of this magnitude in global sources of $\Sigma$ DDT between these two years seems unlikely. Other POPs also showed significant declines with year (log concentration versus year) including $\Sigma$ ClBzs $(\mathrm{P}<0.001), \Sigma \mathrm{HCH}(\mathrm{P}<0.001), \Sigma$ Chlor, and $\Sigma \mathrm{Tox} . \quad \Sigma \mathrm{PCB}$ and mirex concentrations did not significantly decline with year.

There are few other seal data from this region of the north Pacific to compare to POP concentrations seen in this study. The majority of seal data are from regions further north and east of the study site, primarily in the Canadian Arctic (Riget et al., 2010). The two most relevant studies to this work with regard to location and compounds measured were studies conducted on ringed seals from Alaska (Kucklick et al., 2006) and NFS from the northeastern 
coast of Honshu, Japan (Kajiwara et al., 2004). Median concentrations of legacy POPs in male ringed seals collected in 1996 from near Nome, AK in comparison to legacy POPs in NFS from 1997 are shown in Figure 4. Median concentrations of $\Sigma \mathrm{HCH}$ and $\Sigma \mathrm{PCBs}$ were similar between the two seal species. $\Sigma$ DDT in NFSs was approximately twice the concentration observed in ringed seals while $\Sigma$ Chlor was about half. Declining trends in chlordane concentration going from east to west have been observed for marine mammals in this region and the further west sampling location of NFS relative to the ringed seals would be consistent with this trend (Kucklick et al., 2006). The higher concentration of EDDTs in NFS relative to ringed seals suggests an Asian source of DDT to the NFS population.

Concentrations of legacy POPs from adult female NFS collected from the waters of northern Japan (Kajiwara et al., 2004) are also shown in Figure 4. The concentrations shown are the average concentrations from collections of seals made in 1994 and 1997 ( $n=5$ female seals each year). With exception of $\Sigma P C B s$, POP concentrations for seals collected from the two locations (northeast Honshu coast and St. Paul Island) are very similar. While concentrations appear to be similar between the two locations, it should be noted that the samples from Japan were from reproductively mature female seals that have lower blubber concentrations than the juvenile male NFS seals examined in this study. Hickie et al. (Hickie et al., 2005) showed that adult female ringed seal PCB concentrations are reduced to about half of juvenile male concentrations. Extending this observation in ringed seals to the NFS, one would expect to see POPs in juvenile male NFS from coastal Japan at levels twice those observed at St. Paul Island.

\section{Current-use POPs}

Current-use POPs include the PBDE and HBCD flame retardants, as well as the PFAAs. Quality control of the measurement of PFAAs included the analysis of two aliquots of SRM 1946 Organics in Lake Superior Fish Tissue and two additional aliquots of SRM 1947 Organics in Lake Michigan Fish Tissue. With the exception of perfluorooctane sulfonate (PFOS), most PFAAs were below the limits of detection (Table 13). Mean PFOS values determined in the control samples were $2.07 \mathrm{ng} / \mathrm{g}$ (range $1.84 \mathrm{ng} / \mathrm{g}$ to $2.29 \mathrm{ng} / \mathrm{g}$ ) and $6.15 \mathrm{ng} / \mathrm{g}$ (range $5.42 \mathrm{ng} / \mathrm{g}$ to 6.88 $\mathrm{ng} / \mathrm{g}$ ) for SRMs 1946 and 1947, respectively compared to certified values of $2.07 \mathrm{ng} / \mathrm{g} \pm 0.08$ $\mathrm{ng} / \mathrm{g}$ and $6.15 \mathrm{ng} / \mathrm{g} \pm 0.39 \mathrm{ng} / \mathrm{g}$, respectively. PBDEs determined in SRM 1945 Organics in Whale Blubber were within $<20 \%$ of certified values (Table 7). $\alpha-H B C D$ in SRM 1945 averaged $6.1 \mathrm{ng} / \mathrm{g}$ (0.60 ng/g SD).

Concentrations of the PFAAs in NFS livers are given in Table 3. Concentrations of individual PFAAs that were detected were generally in the single $\mathrm{ng} / \mathrm{g}$ to tens of $\mathrm{ng} / \mathrm{g}$ range with concentrations being highest in the odd-chain PFAAs. This is unlike PFAA compound profiles 
seen in aquatic mammals from temperate or subtropical latitudes where profiles are dominated by PFOS (Houde et al., 2006). The pattern observed in the present work is typical for Arctic and subarctic marine mammals and has recently been reported in beluga whales from relatively nearby coastal Alaska and Cook Inlet (Reiner et al., 2011). However, in that study PFOSA dominated in male beluga whales along with PFOS and PFUnA. The magnitude of concentrations was fairly similar to this work with detectable values generally averaging in the $\mathrm{ng} / \mathrm{g}$ to tens of $\mathrm{ng} / \mathrm{g}$ range per compound. Total PFAAs increased significantly (log $\Sigma$ PFAA vs. year; $r^{2}=0.53$ ) and nearly four-fold in seals from 1987 until 2007 which was similar in magnitude to that observed in beluga whales from Alaska (Reiner et al., 2011). There was no significant difference in $\Sigma$ PFAA values among rookeries; however, rookery concentration was highly dependent on year of sampling.

Brominated flame retardant concentrations in NFS are given in Table 14 and summarized in Tables 11 and 12. PBDEs were detected in all samples and HBCDs were detected in 48 of 50 samples. Both $\Sigma$ PBDEs and $\Sigma$ HBCDs concentrations ranged nearly three orders of magnitude with the lowest concentrations generally observed in seals collected during the early years of sampling. As with the perfluorinated compounds, both classes of brominated flame retardants showed dramatic and significant $\left(r^{2}=0.52\right.$ and 0.53 for $\Sigma$ PBDEs and $\Sigma$ HBCDs, respectively) increases with sampling year (Figure 2). Similar increases in PBDEs have been reported in ringed seals from the Canadian Arctic (Ikonomou et al., 2002) and more recently in beluga whales from Alaska (Hoguet et al., 2013). In the current study, there was however a decline in IPBDE concentrations between 2006 and 2007 suggesting that PBDE concentrations may be plateauing in NFS in response to phasing out the use of PBDE mixtures in the northern hemisphere. PBDE 47 dominated the PBDE profile in samples comprising on average $61 \%$ (10 $\% \mathrm{SD}$ ) of total PBDEs. This fraction was consistent among all sampling events suggesting little change in the PBDE profile in the NFS forage fish during the sampling period.

The $\Sigma H B C D$ s were dominated by $\alpha-H B C D$ as seen in other studies (Hoguet et al., 2013). $\gamma-H B C D$ was detected in eight samples although the concentrations were less than $1 \mathrm{ng} / \mathrm{g}$ wet mass. The exponential increase in $\triangle H B C D$ observed here is similar to what was recently reported for beluga whales from Cook Inlet, AK and from the Chukchi Sea, AK (Hoguet et al., 2013). HBCD is still used in North America although this mixture has been recognized by the Stockholm Convention as a candidate for removal from use. The inclusion of HBCD as a POP has sparked debate as the biomagnification potential for this compound is not as high as the legacy POPs. Despite its lower bioaccumulation potential, concentrations in NFS are increasing although the rate of increase with time is half that observed in Alaska beluga whales (slopes 0.12/year versus $0.26 /$ year). 


\section{Conclusions}

Results from this study demonstrate the utility of using archived samples as a source for understanding both geographic and temporal patterns of persistent organic pollutants. The concentrations of POPs in NFS are considerably lower than those observed in other marine mammals from the lower 48 United States; however, the concentrations may still be of concern to animal health as suggested in prior studies. Fortunately, with the exception of mirex, the concentrations of legacy POPs are declining with time in NFS highlighting the success of efforts aimed at curbing POP emissions in the Pacific Region. Current use POPs, however, are increasing in concentration in NFS and continued monitoring of NFS for contaminants is therefore warranted. Based on suggestions from this dataset and other work, PBDEs concentrations have likely peaked and are now declining. This is not true for PFAAs or HBCDs which continue to increase both in this study and the recent work on beluga whales. Archival of NFS tissues should be continued as the population of this animal in the Northern Pacific appears to be declining, and information on contaminants will help in ruling out or ruling in causes for declines. Continued sampling also extends the timeline for monitoring and samples taken now may be useful for identifying trends in the next generation of POPs. When the AMMTAP collection was begun in the late 1980s, legacy POPs were well-known; however, PBDEs, PFAAs, and HBCDs were unrecognized as POPs at that time.

Acknowledgements: The following are acknowledged for their support of AMMTAP work at St. Paul Island over the years: the Aleut Community of St. Paul Island - Phillip A. Zavadil, Aquilina D. Lestenkof, Pamela Lestenkof, Pat Kozloff, and Darleen Melovidov, and from the NMFS Alaska Regional Office - Mike Williams and Steve Zimmerman. A special acknowledgment goes to Terry Spraker, DVM, Colorado State University, who provided special aid at St. Paul in obtaining all of the specimens used in this study. The collection and banking of NFS specimens was also supported by funding from U.S. Department of Interior's Minerals Management Service, U.S. Geological Survey Biological Resources Division, and National Marine Fisheries Service Office of Protected Resource's Marine Mammal Health and Stranding Response Program National Marine Mammal Tissue Bank (Teresa K. Rowles, Program Manager).

Disclaimer: Certain commercial equipment, instruments, or materials are identified in this paper to specify adequately the experimental procedure. Such identification does not imply recommendation or endorsement by the National Institute of Standards and Technology, nor 
does it imply that the materials or equipment identified are necessarily the best available for the purpose.

\section{Literature Cited:}

Antonelis GA, Sinclair EH, Ream RR, Robson BW. Inter-island variation in the diet of female northern fur seals (Callorhinus ursinus) in the Bering Sea. J. Zool. Lond. 1997; 242: 435451.

Becker PR, Gunter EW, Schluter C, Shibata Y, Wise SA. Environmental specimen banking. J. Environ. Monitoring 2006; 8: 776-778.

Becker PR, Wise SA. The US National Biomonitoring Specimen Bank and the Marine Environmental Specimen Bank. JEnviron. Monitoring 2006; 8: 795-799.

Beckmen KB, Blake JE, Ylitalo GM, Stott JL, O'Hara TM. Organochlorine contaminant exposure and associations with hematological and humoral immune functional assays with dam age as a factor in free-ranging northern fur seal pups (Callorhinus ursinus). Mar. Pollut. Bull. 2003; 46: 594-606.

Beckmen KB, Ylitalo GM, Towell RG, Krahn MM, O'Hara TM, Blake JE. Factors affecting organochlorine contaminant concentrations in milk and blood of northern fur seal (Callorhinus ursinus) dams and pups from St. George Island, Alaska. Sci. Total Environ. 1999; 231: 183-200.

Call KA, Ream RR, Johnson D, Sterling JT, Towell RG. Foraging route tactics and site fidelity of adult female northern fur seal (Callorhinus ursinus) around the Pribilof Islands. Deep Sea Res Part II: Topical Studies in Oceanogr. 2008; 55: 1883-1896.

de Wit CA, Herzke D, Vorkamp K. Brominated flame retardants in the Arctic environment-trends and new candidates. Sci. Total Environ. 2010; 408: 2885-2918.

de Wit CA, Muir D. Levels and trends of new contaminants, temporal trends of legacy contaminants and effects of contaminants in the Arctic: preface. Sci. Total Environ. 2010; 408: 2851

Gentry R. Behavior and Ecology of the Northern Fur Seal. Princeton, New Jersey: Princeton University Press, 1997.

Hickie BE, Muir DC, Addison RF, Hoekstra PF. Development and application of bioaccumulation models to assess persistent organic pollutant temporal trends in arctic ringed seal (Phoca hispida) populations. Sci. Total Environ. 2005; 351-352: 413-426. 
Hoguet J, Keller J, Reiner J, Kucklick J, Bryan C, Moors A, Pugh R, Becker PR. Spatial and temporal trends of persistent organic pollutants and mercury in beluga whales (Delphinapterus leucas) from Alaska. Sci. Total Environ 2013; 449:285-294.

Houde M, Bujas TAD, Small J, Wells RS, Fair PA, Bossart GD, Solomon KR, Muir DCG. Biomagnification of Perfluoroalkyl Compounds in the Bottlenose Dolphin (Tursiops truncatus) Food Web. Environ. Sci. Technol. 2006; 40: 4138-4144.

Ikonomou MG, Rayne S, Addison RF. Exponential Increases of the Brominated Flame Retardants, Polybrominated Diphenyl Ethers, in the Canadian Arctic from 1981 to 2000. Environ. Sci. Technol. 2002; 36: 1886-1892.

Kajiwara N, Ueno D, Takahashi A, Baba N, Tanabe S. Polybrominated diphenyl ethers and organochlorines in archived northern fur seal samples from the Pacific coast of Japan, 1972-1998. Environ. Sci. Technol. 2004; 38: 3804-3819.

Kannan K, Franson JC, Bowerman WW, Hansen KJ, Jones PD, Giesy JP. Perfluorooctane sulfonate in fish-eating water birds including bald eagles and albatrosses. Environ. Sci. Technol. 2001; 35: 3065-3070.

Kucklick JR, Krahn MM, Becker PR, Porter BJ, Schantz MM, York GS, O'Hara TM, Wise SA. Persistent organic pollutants in Alaskan ringed seal (Phoca hispida) and walrus (Odobenus rosmarus) blubber. J. Environ. Monitoring 2006; 8: 848-854.

Lahvis GP, Wells RS, Kuehl DW, Stewart JL, Rhinehart HL, Via CS. Decreased lymphocyte responses in free-ranging bottlenose dolphins (Tursiops truncatus) are associated with increased concentrations of PCBs and DDT in peripheral blood. Environ. Health Perspect. 1995; 103: 67-72.

Letcher RJ, Bustnes JO, Dietz R, Jenssen BM, Jorgensen EH, Sonne C, Verreault J, Vijayan MM, Gabrielsen GW. Exposure and effects assessment of persistent organohalogen contaminants in arctic wildlife and fish. Sci. Total Environ. 2010; 408: 2995-3043.

Pugh RS, Ellisor MB, Moors AJ, Porter BJ, Becker PR. Marine Environmental Specimen Bank: Clean Room and Specimen Bank Protocols. NIST Internal Report 7389. National Institute of Standards and Technology, Gaithersburg, Maryland, USA. 2007.

Reiner JL, O'Connell SG, Butt CM, Mabury SA, Small JM, De Silva AO, Muir DC, Delinsky AD, Strynar MJ, Lindstrom AB, Reagen WK, Malinsky M, Schafer S, Kwadijk CJ, Schantz MM, Keller JM. Determination of perfluorinated alkyl acid concentrations in biological standard reference materials. Anal. Bioanal. Chem. 2012; 404: 2683-92.

Reiner JL, O'Connell SG, Moors AJ, Kucklick JR, Becker PR, Keller JM. Spatial and temporal trends of perfluorinated compounds in Beluga Whales (Delphinapterus leucas) from Alaska. Environ Sci Technol 2011; 45: 8129-8136. 
Riget F, Bignert A, Braune B, Stow J, Wilson S. Temporal trends of legacy POPs in Arctic biota, an update. Sci. Total Environ. 2010; 408: 2874-2884.

Simms W, Ross PS. Vitamin A physiology and its application as a biomarker of contaminantrelated toxicity in marine mammals: A review. Toxicol. Industrial Health 2000; 16: 291302.

Towell RG, Ream RR. Decline in northern fur seal (Callorhinus ursinus) pub production on the Pribilof Islands. Marine Mammal Sci. 2006; 22: 486-491.

Zeisler R, Langland JK, Harrison SH. Cryogenic homogenization procedures for biological tissues. Anal. Chem. 983; 55: 2434-2461. 
Table 1: Compounds determined in this work

\begin{tabular}{|c|c|c|c|c|}
\hline Compound or class & $\begin{array}{l}\text { Legacy } \\
\text { POP? }\end{array}$ & $\begin{array}{l}\text { Current } \\
\text { Use POP? }\end{array}$ & $\begin{array}{l}\text { Listed in Stockholm } \\
\text { Convention? }\end{array}$ & Comments \\
\hline Polychlorinated biphenyl (PCBs) & yes & & yes & $\begin{array}{l}\text { Total is the sum of } 58 \text { congeners } \\
\text { or congener pairs }(\Sigma P C B)\end{array}$ \\
\hline Chlordanes & yes & & yes & $\begin{array}{l}\text { Total is the sum of cis- and trans- } \\
\text { chlordane; cis- and trans- } \\
\text { nonachlor, heptachlor, } \\
\text { oxychlordane ( } \Sigma \text { Chlor) }\end{array}$ \\
\hline Hexachlorocyclohexanes (HCHs) & Yes & & Yes & $\begin{array}{l}\text { Total is the sum of } \alpha_{-}^{-}, \beta-\text {, and } \gamma^{-} \\
\mathrm{HCH}(\Sigma \mathrm{HCH})\end{array}$ \\
\hline Mirex & Yes & & Yes & \\
\hline $\begin{array}{l}\text { Toxaphene (sum of four } \\
\text { congeners) }\end{array}$ & Yes & & Yes & $\begin{array}{l}\text { Four congeners were determined } \\
\text { Parlar numbers } 26,32,50 \text {, and } 62 \\
(\Sigma \text { Tox })\end{array}$ \\
\hline $\begin{array}{l}\text { Penta- and hexachlorobenzene } \\
\text { (PeCB and HCB) }\end{array}$ & Yes & & Yes & $\begin{array}{l}\text { Sum is the sum of penta- and } \\
\text { hexachlorobenzene }(\Sigma C B z)\end{array}$ \\
\hline $\begin{array}{l}\text { Dichlorodiphenyl ethane related } \\
\text { compounds (DDTs) }\end{array}$ & Yes & & Yes & $\begin{array}{l}\text { Total DDT is the sum of } 2,4^{\prime}-\text { and } \\
\left.4,4^{\prime}-\text { DDE, DDD and DDT ( } \sum D D T\right)\end{array}$ \\
\hline Perfluorinated alkyl acids (PFAAs) & & Yes & Yes for PFOS & $\begin{array}{l}\text { Total PFAAs is the sum of four to } \\
14 \text { carbon perfluorocarboxylic } \\
\text { acids, perfluorobutane sulfonate, } \\
\text { perfluorohexane sulfonate, } \\
\text { perflurooctane sulfonate, and } \\
\text { perfluorooctanesulfonamide } \\
\text { (IPFAA) }\end{array}$ \\
\hline $\begin{array}{l}\text { Polybrominated diphenyl ethers } \\
\text { (PBDEs) }\end{array}$ & & Yes & Yes & $\begin{array}{l}\text { Sum of PBDE is congeners } 47,99, \\
100,153,154 \text {, and } 155 \text { (SPBDE) }\end{array}$ \\
\hline $\begin{array}{l}\text { Hexabromocyclododecanes } \\
\text { (HBCD) }\end{array}$ & & Yes & Yes--proposed & $\begin{array}{l}\text { HBCDs is limited to } \alpha-H B C D \text { in this } \\
\text { work }\end{array}$ \\
\hline
\end{tabular}


Table 2: Sample Information.

\begin{tabular}{|c|c|c|c|c|c|c|c|c|}
\hline a 692-FRSL- & $\begin{array}{l}\text { Blubber } \\
\text { Storage\# }\end{array}$ & $\begin{array}{c}\text { Liver } \\
\text { Storage\# }\end{array}$ & $\begin{array}{l}\text { Collection } \\
\text { Date }\end{array}$ & Rookery & $\begin{array}{c}\text { Seal } \\
\text { Mass (kg) }\end{array}$ & $\begin{array}{c}\text { Seal } \\
\text { length }(\mathrm{cm})\end{array}$ & $\begin{array}{c}\text { Blubber } \\
\text { thickness }(\mathrm{cm})\end{array}$ & $\begin{array}{c}\text { Blubber Lipid } \\
\text { content (\%) }\end{array}$ \\
\hline 1 & MM1B004 & MM1L001 & $7 / 28 / 1987$ & Polavina & 56.3 & 114 & 1.5 & 51.2 \\
\hline 2 & MM1B008 & MM1L005 & $7 / 28 / 1987$ & Polavina & 77.6 & 117.3 & 2.5 & 73.0 \\
\hline 3 & MM1B012 & MM1L009 & $7 / 28 / 1987$ & Polavina & 84 & 124 & 3 & 70.8 \\
\hline 4 & MM1B016 & MM1L013 & $7 / 29 / 1987$ & Northeast & 64.7 & 111.4 & 2.5 & 69.6 \\
\hline 5 & MM1B020 & MM1L017 & $7 / 29 / 1987$ & Northeast & 58.7 & 110.4 & 3 & 80.7 \\
\hline 6 & MM4B097 & MM4L095 & $7 / 23 / 1990$ & Zapadni & 21.8 & 97.8 & 1.2 & 62.5 \\
\hline 7 & MM4B100 & MM4L098 & $7 / 23 / 1990$ & Zapadni & 23 & 103.5 & 0.9 & 69.5 \\
\hline 8 & MM4B103 & MM4L101 & $7 / 23 / 1990$ & Zapadni & 21.3 & 103.5 & 1.1 & 63.2 \\
\hline 9 & MM4B106 & MM4L104 & $7 / 23 / 1990$ & Zapadni & $n a^{b}$ & na & na & 72.4 \\
\hline 10 & MM4B109 & MM4L107 & $7 / 24 / 1990$ & Reef & 15.8 & 94.6 & 0.8 & 50.6 \\
\hline 11 & MM4B112 & MM4L110 & $7 / 24 / 1990$ & Reef & 17.3 & 43.2 & 0.7 & 45.1 \\
\hline 12 & MM4B115 & MM4L113 & $7 / 24 / 1990$ & Reef & 20.2 & 99.1 & 1 & 57.8 \\
\hline 13 & MM4B118 & MM4L116 & $7 / 27 / 1990$ & Reef & 20.2 & na & 1 & 76.4 \\
\hline 15 & MM4B124 & MM4L122 & $7 / 24 / 1990$ & Reef & 17.4 & 104.1 & 1.2 & 42.9 \\
\hline 16 & MM12B648 & MM12L646 & 8/6/1997 & Zapadni & na & 99.1 & too thin & 67.0 \\
\hline 17 & MM12B652 & MM12L650 & 8/6/1997 & Zapadni & na & 110.5 & too thin & 57.0 \\
\hline 18 & MM12B656 & MM12L654 & 8/6/1997 & Zapadni & na & 111.8 & too thin & 65.5 \\
\hline 19 & MM12B660 & MM12L658 & $8 / 6 / 1997$ & Zapadni & na & 123.2 & too thin & 57.0 \\
\hline 20 & MM12B664 & MM12L662 & 8/6/1997 & Zapadni & na & 111.8 & too thin & 65.0 \\
\hline 22 & MM16B169C & MM16L167C & $7 / 10 / 2000$ & Polavina & na & na & na & 62.5 \\
\hline 23 & MM16B172C & MM16L170C & $7 / 10 / 2000$ & Polavina & na & na & na & 78.6 \\
\hline 24 & MM16B175C & MM16L173C & $7 / 10 / 2000$ & Polavina & na & na & na & 71.0 \\
\hline 25 & MM16B178C & MM16L176C & $7 / 10 / 2000$ & Polavina & na & na & na & 60.4 \\
\hline 26 & MM16B181C & MM16L179C & $7 / 10 / 2000$ & Polavina & na & na & na & 79.9 \\
\hline 27 & MM16B184C & MM16L182C & $7 / 10 / 2000$ & Polavina & na & na & na & 68.5 \\
\hline 28 & MM16B187C & MM16L185C & $7 / 10 / 2000$ & Polavina & na & na & na & 76.8 \\
\hline 31 & MM16B196C & MM16L194C & $7 / 10 / 2000$ & Polavina & na & na & na & 74.8 \\
\hline 38 & MM22B819C & MM22L818C & $7 / 22 / 2006$ & Reef & na & na & na & 75.8 \\
\hline 39 & MM22B822C & MM22L820C & $7 / 22 / 2006$ & Reef & na & na & na & 75.4 \\
\hline 40 & MM22B825C & MM22L823C & $7 / 22 / 2006$ & Reef & na & na & na & 65.3 \\
\hline 41 & MM22B828C & MM22L826C & $7 / 22 / 2006$ & Reef & na & na & na & 81.9 \\
\hline 42 & MM22B831C & MM22L829C & $7 / 22 / 2006$ & Reef & na & na & na & 70.4 \\
\hline 44 & MM22B796C & MM22L794C & $7 / 22 / 2006$ & Reef & na & na & na & 82.2 \\
\hline 45 & MM22B799C & MM22L797C & $7 / 22 / 2006$ & Reef & na & na & na & 84.3 \\
\hline 46 & MM22B808C & MM22L806C & $7 / 22 / 2006$ & Reef & na & na & na & 70.7 \\
\hline 47 & MM22B802C & MM22L800C & $7 / 22 / 2006$ & Reef & na & na & na & 77.5 \\
\hline 48 & MM22B836C & MM22L834C & $7 / 22 / 2006$ & Reef & na & na & na & 83.6 \\
\hline 52 & MM22B899C & MM22L897C & $7 / 8 / 2007$ & Polavina & na & na & na & 74.2 \\
\hline$\overline{53}$ & MM22B902C & MM22L900C & $7 / 8 / 2007$ & Polavina & na & na & na & 77.9 \\
\hline 54 & MM22B905C & MM22L903C & $7 / 8 / 2007$ & Polavina & na & na & na & 63.7 \\
\hline 55 & MM22B908C & MM22L906C & $7 / 8 / 2007$ & Polavina & na & na & na & 56.1 \\
\hline 56 & MM22B911C & MM22L909C & $7 / 8 / 2007$ & Polavina & na & na & na & 68.1 \\
\hline 57 & MM22B914C & MM22L912C & $7 / 8 / 2007$ & Polavina & na & na & na & 76.5 \\
\hline 58 & MM22B917C & MM22L915C & $7 / 8 / 2007$ & Polavina & na & na & na & 68.3 \\
\hline 59 & MM22B920C & MM227918C & $7 / 8 / 2007$ & Polavina & na & na & na & 64.1 \\
\hline 60 & MM22B923C & MM22L921C & $7 / 8 / 2007$ & Polavina & na & na & na & 70.3 \\
\hline 61 & MM22B926C & MM22L924C & $7 / 8 / 2007$ & Polavina & na & na & na & 65.4 \\
\hline
\end{tabular}

${ }^{a}$ MM1L017 sample was never located and excluded from the analysis. " "na" not available 
Table 3: Perfluorinated alkyl acids (ng/g wet mass) in northern fur seal liver

\begin{tabular}{|c|c|c|c|c|c|c|c|c|c|}
\hline FRSL- & Storage ID & PFBA & PFPeA & PFHxA & PFHpA & PFOA & PFNA & PFDA & PFUnA \\
\hline 1 & MM1L001 & $<3.7$ & $<1.1$ & $<0.5$ & $<0.4$ & $<1.1$ & 0.92 & $<0.9$ & 1.5 \\
\hline 2 & MM1L005 & $<3.9$ & $<1.1$ & $<0.6$ & $<0.5$ & $<1.1$ & 0.68 & $<0.9$ & 3.3 \\
\hline 3 & MM1L009 & $<4.6$ & $<1.3$ & $<0.7$ & $<0.5$ & $<1.3$ & 3.3 & 1.7 & 10.9 \\
\hline 4 & MM1L013 & $<1.1$ & $<1.2$ & $<0.2$ & $<2.00$ & $<0.5$ & 2.4 & $<0.4$ & 17.8 \\
\hline 5 & missing & -- & -- & -- & -- & -- & -- & -- & -- \\
\hline 6 & MM4L095 & $<2.5$ & $<0.7$ & $<0.4$ & $<0.3$ & $<0.7$ & 1.5 & $<0.6$ & 1.68 \\
\hline 8 & MM4L101 & $<5.9$ & $<1.7$ & $<0.8$ & $<0.7$ & $<1.7$ & 1.3 & $<1.4$ & 2.7 \\
\hline 9 & MM4L104 & $<7.4$ & $<2.0$ & $<1.1$ & $<0.9$ & $<2.1$ & 1.2 & $<1.8$ & 5.2 \\
\hline 10 & MM4L107 & $<2.1$ & $<2.4$ & $<0.3$ & $<3.9$ & $<1.0$ & 3.7 & $<0.8$ & 13.0 \\
\hline 11 & MM4L110 & $<1.2$ & $<1.4$ & $<0.2$ & $<2.3$ & $<0.6$ & 0.98 & $<0.5$ & 34.6 \\
\hline 12 & MM4L113 & $<4.5$ & $<1.2$ & $<0.7$ & $<0.5$ & $<1.3$ & 3.3 & $<1.1$ & 4.3 \\
\hline 13 & MM4L116 & $<4.7$ & $<1.3$ & $<0.7$ & $<0.5$ & $<1.3$ & 0.56 & $<1.1$ & 0.55 \\
\hline 14 & MM4L119 & $<5.4$ & $<1.5$ & $<0.8$ & $<0.6$ & $<1.5$ & 1.5 & $<1.3$ & 4.2 \\
\hline 16 & MM12L646 & $<2.4$ & $<0.7$ & $<0.3$ & $<0.3$ & $<0.7$ & 2.7 & 0.87 & 9.3 \\
\hline 17 & MM12L650 & $<5.6$ & $<1.6$ & $<0.8$ & $<0.7$ & $<1.6$ & 1.9 & $<1.3$ & 6.7 \\
\hline 18 & MM12L654 & $<4.0$ & $<1.2$ & $<0.6$ & $<0.5$ & $<1.1$ & 4.1 & 1.3 & 6.4 \\
\hline 19 & MM12L658 & $<4.2$ & $<1.2$ & $<0.6$ & $<0.5$ & $<1.2$ & 4.5 & 1.2 & 6.9 \\
\hline 20 & MM12L662 & $<3.9$ & $<1.1$ & $<0.6$ & $<0.5$ & $<1.1$ & 8.5 & 1.4 & 12.2 \\
\hline 22 & MM16L167 & $<1.8$ & $<2.0$ & $<0.3$ & $<3.3$ & $<0.8$ & $<1.35$ & $<0.7$ & 8.8 \\
\hline 23 & MM16L170 & $<2.2$ & $<2.5$ & $<0.3$ & $<4.1$ & $<1.1$ & 5.0 & $<0.8$ & 75.7 \\
\hline 24 & MM16L173 & $<1.5$ & $<1.8$ & $<0.2$ & $<2.9$ & $<0.7$ & 6.0 & $<0.6$ & 57.0 \\
\hline 25 & MM16L176 & $<1.4$ & $<1.6$ & $<0.2$ & $<2.6$ & $<0.7$ & 1.9 & $<0.5$ & 41.5 \\
\hline 26 & MM16L179 & $<2.1$ & $<2.4$ & $<0.3$ & $<3.9$ & $<1.0$ & 18.8 & $<0.8$ & 11.5 \\
\hline 27 & MM16L182 & $<1.3$ & $<1.5$ & $<0.2$ & $<2.5$ & $<0.6$ & 3.3 & $<0.5$ & 24.6 \\
\hline 28 & MM16L185 & $<1.0$ & $<1.2$ & $<0.2$ & $<2.0$ & $<0.5$ & 2.5 & $<0.4$ & 26.9 \\
\hline 29 & MM16L188 & $<3.0$ & $<3.5$ & $<0.4$ & $<5.7$ & $<1.4$ & 6.0 & $<1.1$ & 13.3 \\
\hline 38 & MM22L818 & $<1.0$ & $<1.1$ & $<0.1$ & $<1.9$ & $<0.5$ & 3.3 & $<0.4$ & 51.7 \\
\hline 39 & MM22L820 & $<1.4$ & $<1.6$ & $<0.2$ & $<2.6$ & $<0.7$ & 11.8 & $<0.5$ & 115 \\
\hline 40 & MM22L823 & $<1.3$ & $<1.5$ & $<0.2$ & $<2.5$ & $<0.6$ & 7.6 & $<0.5$ & 34.5 \\
\hline 41 & MM22L826 & $<1.5$ & $<1.7$ & $<0.2$ & $<2.7$ & $<0.7$ & 13.1 & $<0.5$ & 105 \\
\hline 42 & MM22L829 & $<1.2$ & $<1.4$ & $<0.2$ & $<2.3$ & $<0.6$ & 10.1 & $<0.5$ & 21.0 \\
\hline 44 & MM22L794 & $<1.4$ & $<1.6$ & $<0.2$ & $<2.6$ & $<0.7$ & 3.7 & $<0.5$ & 15.5 \\
\hline 45 & MM22L797 & $<1.2$ & $<1.3$ & $<0.2$ & $<2.2$ & $<0.6$ & 9.7 & $<0.4$ & 138 \\
\hline 46 & MM22L806 & $<1.4$ & $<1.6$ & $<0.2$ & $<2.6$ & $<0.7$ & 4.1 & $<0.5$ & 23.1 \\
\hline 47 & MM22L800 & $<1.8$ & $<2.1$ & $<0.3$ & $<3.4$ & $<0.9$ & 7.0 & $<0.7$ & 31.6 \\
\hline 48 & MM22L834 & $<1.5$ & $<1.7$ & $<0.2$ & $<2.8$ & $<0.7$ & 5.8 & $<0.6$ & 17.3 \\
\hline 52 & MM22L897 & $<1.2$ & $<1.4$ & $<0.2$ & $<2.2$ & $<0.6$ & 6.0 & $<0.4$ & 122 \\
\hline 53 & MM22L900 & $<1.3$ & $<1.5$ & $<0.2$ & $<2.5$ & $<0.6$ & 7.9 & $<0.5$ & 22.2 \\
\hline 54 & MM22L903 & $<2.5$ & $<2.8$ & $<0.4$ & $<4.6$ & $<1.2$ & 3.0 & $<0.9$ & 38.0 \\
\hline 55 & MM22L906 & $<2.6$ & $<3.0$ & $<0.4$ & $<4.9$ & $<1.3$ & 7.9 & $<1.0$ & 16.8 \\
\hline 56 & MM22L909 & $<1.4$ & $<1.6$ & $<0.2$ & $<2.7$ & $<0.7$ & 4.0 & $<0.5$ & 70.4 \\
\hline 57 & MM22L912 & $<1.2$ & $<1.3$ & $<0.2$ & $<2.2$ & $<0.6$ & 19.8 & $<0.4$ & 17.2 \\
\hline 58 & MM22L915 & $<1.4$ & $<1.6$ & $<0.2$ & $<2.7$ & $<0.7$ & 6.0 & $<0.5$ & 90.9 \\
\hline 59 & MM22L918 & $<1.3$ & $<1.5$ & $<0.2$ & $<2.4$ & $<0.6$ & 8.2 & $<0.5$ & 70.3 \\
\hline 60 & MM22L921 & $<2.2$ & $<2.6$ & $<0.3$ & $<4.2$ & $<1.1$ & 5.5 & $<0.8$ & 29.9 \\
\hline 61 & MM22L924 & $<2.0$ & $<2.3$ & $<0.3$ & $<3.8$ & $<1.0$ & 15.5 & $<0.8$ & 66.9 \\
\hline
\end{tabular}

PFBA = perfluorobutanoic acid, PFPeA = perfluoropentanoic acid, $\mathrm{PFHXA}=$ perfluorohexanonic acid, $\mathrm{PFOA}=$ perfluorooctanoic acid, PFNA = perfluornonanoic acid, PFDA = perfluorodecanoic acid, $\mathrm{PFUnA}=$ perfluoroundecanoic acid 
Table 3 (cont.): Perfluorinated alkyl acids (ng/g wet mass) in northern fur seal liver

\begin{tabular}{|c|c|c|c|c|c|c|c|c|}
\hline FRSL- & Storage ID & PFDoA & PFTriA & PFTA & PFBS & PFHxS & PFOS & PFOSA \\
\hline 1 & MM1L001 & $<0.4$ & 0.77 & $<0.3$ & $<0.1$ & 0.11 & 2.9 & 0.73 \\
\hline 2 & MM1L005 & $<0.4$ & 0.76 & $<0.3$ & $<0.2$ & 0.12 & 1.7 & 1.6 \\
\hline 3 & MM1L009 & 2.2 & 1.8 & 0.97 & $<0.2$ & 0.47 & 3.4 & 1.6 \\
\hline 4 & MM1L013 & $<0.2$ & 1.8 & $<0.3$ & $<0.1$ & 0.14 & 4.9 & $<0.2$ \\
\hline 5 & missing & -- & -- & -- & -- & -- & -- & -- \\
\hline 6 & MM4L095 & $<0.2$ & 0.82 & $<0.2$ & $<0.1$ & 0.18 & 3.6 & 0.82 \\
\hline 7 & MM4L098 & $<0.3$ & 2.5 & $<0.5$ & $<0.2$ & 0.26 & 7.7 & $<0.3$ \\
\hline 8 & MM4L101 & $<0.6$ & 1.4 & $<0.4$ & $<0.2$ & 0.19 & 3.1 & 0.57 \\
\hline 9 & MM4L104 & $<0.7$ & 1.8 & 0.72 & $<0.3$ & 0.26 & 5.2 & 1.5 \\
\hline 10 & MM4L107 & $<0.4$ & 0.81 & $<0.7$ & $<0.2$ & 0.20 & 4.0 & 0.63 \\
\hline 11 & MM4L110 & $<0.2$ & 9.1 & $<0.4$ & $<0.1$ & $<0.1$ & 4.7 & 0.99 \\
\hline 12 & MM4L113 & $<0.4$ & 2.2 & $<0.3$ & $<0.2$ & 0.40 & 8.0 & 1.4 \\
\hline 13 & MM4L116 & $<0.5$ & 1.9 & $<0.3$ & 0.62 & 0.08 & 1.1 & 0.08 \\
\hline 14 & MM4L119 & $<0.5$ & 1.2 & $<0.4$ & $<0.2$ & 0.20 & 3.8 & 1.2 \\
\hline 16 & MM12L646 & 2.8 & 3.0 & 1.3 & $<0.1$ & 0.19 & 5.4 & 3.2 \\
\hline 17 & MM12L650 & $<0.6$ & 2.4 & 0.79 & $<0.2$ & 0.25 & 4.1 & 2.4 \\
\hline 18 & MM12L654 & $<0.4$ & 1.7 & $<0.3$ & $<0.2$ & 0.24 & 8.1 & 1.2 \\
\hline 19 & MM12L658 & $<0.4$ & 2.4 & $<0.3$ & $<0.2$ & 0.11 & 7.2 & 0.98 \\
\hline 20 & MM12L662 & 1.4 & 4.7 & 0.81 & $<0.1$ & 0.36 & 13.6 & 2.8 \\
\hline 22 & MM16L167 & $<0.3$ & $<0.3$ & $<0.6$ & $<0.2$ & $<0.2$ & 2.9 & $<0.3$ \\
\hline 23 & MM16L170 & $<0.4$ & 2.2 & $<0.7$ & $<0.2$ & $<0.2$ & 3.1 & $<0.3$ \\
\hline 24 & MM16L173 & $<0.3$ & 2.7 & $<0.5$ & $<0.2$ & 0.67 & 15.3 & $<0.2$ \\
\hline 25 & MM16L176 & $<0.3$ & 4.7 & $<0.4$ & $<0.2$ & 0.30 & 3.1 & 3.4 \\
\hline 26 & MM16L179 & $<0.4$ & 5.4 & $<0.7$ & $<0.2$ & $<0.2$ & 2.2 & 1.0 \\
\hline 27 & MM16L182 & $<0.2$ & 6.6 & $<0.4$ & $<0.1$ & 0.21 & 1.7 & 4.0 \\
\hline 28 & MM16L185 & $<0.2$ & 1.2 & $<0.3$ & $<0.1$ & $<0.1$ & 0.93 & $<0.2$ \\
\hline 29 & MM16L188 & $<0.6$ & $<0.5$ & $<1.0$ & $<0.3$ & 0.31 & 4.6 & 1.1 \\
\hline 38 & MM22L818 & $<0.2$ & 0.67 & $<0.3$ & $<0.1$ & 0.22 & 3.6 & $<0.2$ \\
\hline 39 & MM22L820 & $<0.3$ & 24.0 & $<0.4$ & $<0.2$ & 0.22 & 2.4 & 0.70 \\
\hline 40 & MM22L823 & $<0.2$ & 2.62 & $<0.4$ & $<0.1$ & 0.20 & 2.7 & 0.23 \\
\hline 41 & MM22L826 & $<0.3$ & 25.9 & $<0.5$ & $<0.2$ & 0.41 & 17.5 & $<0.2$ \\
\hline 42 & MM22L829 & $<0.2$ & 0.26 & $<0.4$ & $<0.1$ & $<0.1$ & 5.6 & $<0.2$ \\
\hline 44 & MM22L794 & $<0.2$ & $<0.2$ & $<0.4$ & $<0.2$ & $<0.1$ & 1.3 & $<0.2$ \\
\hline 45 & MM22L797 & $<0.2$ & 11.4 & $<0.4$ & $<0.1$ & $<0.1$ & 4.2 & 0.36 \\
\hline 46 & MM22L806 & $<0.3$ & 5.4 & $<0.4$ & $<0.2$ & 0.46 & 8.8 & $<0.2$ \\
\hline 47 & MM22L800 & $<0.3$ & 5.4 & $<0.6$ & $<0.2$ & $<0.2$ & 2.1 & 0.99 \\
\hline 48 & MM22L834 & $<0.3$ & 4.2 & $<0.5$ & $<0.2$ & $<0.2$ & 2.6 & 0.47 \\
\hline 52 & MM22L897 & $<0.2$ & 1.6 & $<0.4$ & $<0.1$ & 0.24 & 7.7 & $<0.2$ \\
\hline 53 & MM22L900 & $<0.3$ & 9.1 & $<0.4$ & $<0.1$ & 0.36 & 3.9 & 1.47 \\
\hline 54 & MM22L903 & $<0.5$ & 6.5 & $<0.8$ & $<0.3$ & $<0.3$ & 2.7 & 0.48 \\
\hline 55 & MM22L906 & $<0.5$ & 2.2 & $<0.8$ & $<0.3$ & $<0.3$ & 10.0 & 0.78 \\
\hline 56 & MM22L909 & $<0.3$ & 13.8 & $<0.4$ & $<0.2$ & 0.80 & 15.8 & 0.67 \\
\hline 57 & MM22L912 & $<0.2$ & 1.6 & $<0.4$ & $<0.1$ & 0.33 & 3.3 & 0.42 \\
\hline 58 & MM22L915 & $<0.3$ & 4.8 & $<0.5$ & $<0.2$ & 0.43 & 8.4 & 0.74 \\
\hline 59 & MM22L918 & $<0.2$ & 4.7 & $<0.4$ & $<0.1$ & $<0.1$ & 6.09 & $<0.2$ \\
\hline 60 & MM22L921 & $<0.4$ & 2.7 & $<0.7$ & $<0.2$ & 1.6 & 14.4 & $<0.3$ \\
\hline 61 & MM22L924 & $<0.4$ & 1.6 & $<0.6$ & $<0.2$ & 0.37 & 14.4 & 0.32 \\
\hline
\end{tabular}

PFDoA = perfluorododecanoic acid, PFTriA = perfluorotridecanoic acid, PFTA = perfluorotetradecanoic acid, PFHxS = perfluorohexansulfonate, PFOS = perfluorooctane sulfonate, PFOSA = perfluorooctanesulfonamide 
Table 4: Mass fraction of vitamins ( $\mathrm{mg} / \mathrm{kg}$ wet mass) determined in the liver control material

\begin{tabular}{lccc}
\hline Sample & SRetinol & $\alpha$-Tocopherol & $\gamma$-Tocopherol \\
\hline QC97LH02-1 & 151 & 12700 & 1600 \\
QC97LH02-1 & 144 & 8280 & 1580 \\
QC97LH02-1 & 123 & 7340 & 1370 \\
Mean & 139 & 9430 & 1520 \\
1 SD & 15 & 2850 & 131 \\
RSD (\%) & 10 & 30 & 9 \\
\hline
\end{tabular}


Table 5: Mass fraction of vitamins ( $\mathrm{mg} / \mathrm{kg}$ wet mass) determined in northern fur seal livers

\begin{tabular}{|c|c|c|c|c|}
\hline FRSL- & Storage\# & $\sum$ Retinol & $\alpha$-Tocopherol & $\gamma$-Tocopherol \\
\hline 1 & MM1L001 & 300 & 14000 & 801 \\
\hline 2 & MM1L005 & 27.5 & 15900 & 735 \\
\hline 3 & MM1L009 & 157 & 7800 & 1310 \\
\hline 4 & MM1L013 & 52.4 & 4790 & 657 \\
\hline 5 & missing & -- & -- & -- \\
\hline 6 & MM4L095 & 43.9 & 9780 & 618 \\
\hline 7 & MM4L098 & 21.7 & 12800 & nd \\
\hline 8 & MM4L101 & 34.8 & 14700 & nd \\
\hline 9 & MM4L104 & 54.1 & 12600 & 1290 \\
\hline 10 & MM4L107 & 116 & 12700 & 902 \\
\hline 11 & MM4L110 & 12.3 & 10400 & 853 \\
\hline 12 & MM4L113 & 53.0 & 9370 & 2010 \\
\hline 13 & MM4L116 & 63.3 & 3000 & 685 \\
\hline 14 & MM4L119 & 61.6 & 10300 & 597 \\
\hline 15 & MM4L122 & 60.2 & 9140 & 1720 \\
\hline 16 & MM12L646 & 11.5 & nd & nd \\
\hline 17 & MM12L650 & 671 & 15300 & $<L O D$ \\
\hline 18 & MM12L654 & 69.3 & 5680 & 571 \\
\hline 19 & MM12L658 & 59.9 & 13500 & nd \\
\hline 20 & MM12L662 & 39.6 & 6340 & nd \\
\hline 22 & MM16L167 & 409 & 11300 & nd \\
\hline 23 & MM16L170 & 98.3 & 11700 & nd \\
\hline 24 & MM16L173 & 12.1 & 5710 & nd \\
\hline 25 & MM16L176 & 165 & 14600 & 594 \\
\hline 26 & MM16L179 & 600 & 15400 & nd \\
\hline 27 & MM16L182 & 30.6 & 5260 & nd \\
\hline 28 & MM16L185 & 248 & 17700 & nd \\
\hline 29 & MM16L188 & 525 & 13600 & nd \\
\hline 30 & MM16L191 & 11.3 & 3650 & 736 \\
\hline 31 & MM16L194 & 251 & 11600 & nd \\
\hline 38 & MM22L818 & 21.9 & 6190 & 1600 \\
\hline 39 & MM22L820 & 21.8 & 2950 & nd \\
\hline 40 & MM22L823 & 26.4 & 10300 & nd \\
\hline 41 & MM22L826 & 11.1 & 4970 & 1280 \\
\hline 42 & MM22L829 & 12.9 & nd & nd \\
\hline 44 & MM22L794 & 14.4 & 11300 & 1200 \\
\hline 45 & MM22L797 & 98.2 & 16700 & 787 \\
\hline 46 & MM22L806 & 203 & 15200 & 578 \\
\hline 47 & MM22L800 & 38.8 & 5850 & 527 \\
\hline 48 & MM22L834 & 106 & nd & nd \\
\hline 52 & MM22L897 & 147 & 23400 & 729 \\
\hline 53 & MM22L900 & 20.2 & nd & nd \\
\hline 54 & MM22L903 & 13.0 & 9390 & 501 \\
\hline 55 & MM22L906 & 82.8 & 6740 & 741 \\
\hline 56 & MM22L909 & 44.9 & 10000 & 1220 \\
\hline 57 & MM22L912 & 4.80 & nd & nd \\
\hline 58 & MM22L915 & 75.6 & 7790 & 710 \\
\hline 59 & MM227918 & 654 & 10900 & 1050 \\
\hline 60 & MM22L921 & 219 & 7820 & 996 \\
\hline 61 & MM22L924 & 134 & nd & nd \\
\hline
\end{tabular}

nd: not detected 
Table 6: Mass fraction ( $\mathrm{mg} / \mathrm{kg}$-wet mass) of vitamins in northern fur seal livers by rookery

\begin{tabular}{|c|c|c|c|c|c|c|c|}
\hline Rookery & $\mathbf{n}$ & $\begin{array}{c}\text { Mean } \\
\Sigma \text { Retinol }\end{array}$ & $\begin{array}{c}\text { Mean } \\
\alpha-\text { Tocopherol }\end{array}$ & $\begin{array}{c}\text { Mean } \\
\gamma \text {-Tocopherol }\end{array}$ & $\begin{array}{c}\text { Stdev } \\
\text { ERetinol }\end{array}$ & $\begin{array}{c}\text { Stdev } \\
\alpha-\text { Tocopherol }\end{array}$ & $\begin{array}{c}\text { Stdev } \\
\gamma \text {-Tocopherol }\end{array}$ \\
\hline Northeast & 1 & 52.4 & 4790 & 657 & & & \\
\hline Polavina & 23 & 184 & 11200 & 843 & 195 & 4800 & 246 \\
\hline Reef & 16 & 57.6 & 9160 & 1060 & 52.0 & 4180 & 497 \\
\hline Zapadni & 9 & 112 & 11400 & 826 & 210 & 3700 & 402 \\
\hline
\end{tabular}


Table 7: Mass fractions (ng/g wet mass) of compounds determined in aliquots of SRM 1945 used as a control material in this study. Italicized bold values are reference values. Reference values differ from certified values in that all sources of uncertainty have not been accounted for during certification.

\begin{tabular}{|c|c|c|c|c|c|c|c|}
\hline \multirow[t]{2}{*}{ Compound } & \multicolumn{6}{|c|}{ SRM 1945 Aliquot } & \multirow{2}{*}{$\begin{array}{c}\text { Certified or } \\
\text { Reference Value }\end{array}$} \\
\hline & 1 & 2 & 3 & 4 & mean & SD & \\
\hline pentachlorobenzene & 2.3 & 2.4 & 2.5 & 2.8 & 2.5 & 0.2 & $2.09 \pm 0.53$ \\
\hline$\alpha-\mathrm{HCH}$ & 20.5 & 19.3 & 20.5 & 20.2 & 20.1 & 0.6 & $16.9 \pm 1.4$ \\
\hline $\mathrm{HCB}$ & 28.4 & 31.6 & 31.9 & 32.3 & 31.0 & 1.8 & $30.6 \pm 1.5$ \\
\hline$\gamma-\mathrm{HCH}$ & 2.9 & 2.6 & 2.7 & 2.8 & 2.8 & 0.1 & $3.18 \pm 0.01$ \\
\hline oxychlordane & 21.0 & 20.6 & 19.9 & 20.3 & 20.5 & 0.5 & $21.2 \pm 1.1$ \\
\hline trans-chlordane & 20.3 & 16.8 & 16.9 & 17.2 & 17.8 & 1.7 & $11.8 \pm 0.5$ \\
\hline cis-chlordane & 50.4 & 52.0 & 51.0 & 56.1 & 52.4 & 2.6 & $48.1 \pm 1.6$ \\
\hline trans-nonachlor & 182 & 181 & 183 & 182 & 182 & 0.8 & $198 \pm 16$ \\
\hline cis-nonachlor & 44.9 & 54.6 & 62.0 & 44.6 & 51.5 & 8.4 & $45.8 \pm 3.3$ \\
\hline Parlar 26 & 86.0 & 73.9 & 72.8 & 81.7 & 78.6 & 6.3 & $41.8 \pm 2.8$ \\
\hline Parlar 32 & 7.3 & 8.0 & 8.3 & 8.5 & 8.0 & 0.5 & no value \\
\hline Parlar 50 & 139 & 107 & 108 & 115 & 117 & 15 & $69.7 \pm 5.5$ \\
\hline Parlar 62 & 77.2 & 48.6 & 48.9 & 52.4 & 56.8 & 14 & $37.2 \pm 3.8$ \\
\hline PBDE 28 & 1.4 & 2.2 & 1.8 & 2.0 & 1.8 & 0.3 & $2.66 \pm 0.37$ \\
\hline PBDE 47 & 42.3 & 38.0 & 41.1 & 36.9 & 39.6 & 2.5 & $39.6 \pm 0.2$ \\
\hline PBDE 100 & 10.0 & 10.9 & 10.3 & 11.8 & 10.8 & 0.8 & $10.3 \pm 1.1$ \\
\hline PBDE 99 & 17.9 & 17.7 & 17.2 & 16.7 & 17.4 & 0.52 & $18.9 \pm 2.3$ \\
\hline PBDE 155 & 3.3 & 2.5 & 2.5 & 2.5 & 2.7 & 0.4 & $4.45 \pm 0.93$ \\
\hline PBDE 154 & 18.2 & 13.3 & 14.5 & 13.9 & 15.0 & 2.2 & $13.3 \pm 1.7$ \\
\hline PBDE 153 & 8.5 & 6.2 & 6.7 & 6.1 & 6.9 & 1.1 & $8.34 \pm 0.55$ \\
\hline$\alpha-H B C D$ & 5.9 & 7.0 & 5.7 & 5.6 & 6.1 & 0.6 & no value \\
\hline
\end{tabular}


Table 8: Concentrations ( $\mathrm{ng} / \mathrm{g}$ wet mass) of polychlorinated biphenyls congeners determined in aliquots of SRM 1945 used as a control material in this study. Italicized bold values are reference values.

Reference values differ from certified values in that all sources of uncertainty have not been accounted for during certification.

\begin{tabular}{|c|c|c|c|c|c|c|c|}
\hline \multirow[t]{2}{*}{ Congener } & \multicolumn{6}{|c|}{ SRM 1945 Aliquot } & \multirow{2}{*}{$\begin{array}{c}\text { Certified or } \\
\text { Reference Values }\end{array}$} \\
\hline & 1 & 2 & 3 & 4 & Mean & SD & \\
\hline PCB 18 & 4.3 & 4.4 & 4.3 & 4.7 & 4.4 & 0.2 & $4.35 \pm 0.56$ \\
\hline PCB 31/28 & 16.1 & 17.2 & 15.9 & 16.6 & 16.4 & 0.6 & 16.7 \\
\hline PCB 52 & 42.3 & 41.7 & 41.9 & 41.4 & 41.8 & 0.4 & $40.7 \pm 1.3$ \\
\hline PCB 49 & 17.8 & 17.0 & 18.8 & 18.4 & 18.0 & 0.8 & $18.3 \pm 0.1$ \\
\hline PCB 44 & 12.8 & 12.7 & 12.8 & 12.9 & 12.8 & 0.1 & $12.1 \pm 0.5$ \\
\hline PCB 95 & 31.9 & 32.8 & 31.9 & 34.1 & 32.7 & 1.0 & $33.9 \pm 0.5$ \\
\hline PCB 74 & 21.6 & 22.8 & 20.8 & 21.9 & 21.8 & 0.8 & $21.6 \pm 7.8$ \\
\hline PCB 66 & 23.1 & 22.4 & 21.7 & 22.0 & 22.3 & 0.6 & $22.4 \pm 0.5$ \\
\hline PCB 92 & 22.8 & 23.3 & 23.6 & 23.6 & 23.3 & 0.4 & $23.4 \pm 3.9$ \\
\hline PCB 56 & 7.8 & 7.3 & 7.9 & 8.0 & 7.8 & 0.3 & $7.5 \pm 1.8$ \\
\hline PCB 101 & 81.5 & 82.9 & 81.4 & 79.3 & 81.3 & 1.5 & $78 \pm 12$ \\
\hline РСB 99 & 60.0 & 62.9 & 56.9 & 60.1 & 60.0 & 2.5 & $58.5 \pm 5.2$ \\
\hline PCB 87 & 21.8 & 20.7 & 21.8 & 19.1 & 20.9 & 1.3 & $20.6 \pm 2.6$ \\
\hline PCB 110 & 34.3 & 34.7 & 34.2 & 34.7 & 34.5 & 0.3 & $33.8 \pm 2.3$ \\
\hline PCB 82 & 4.7 & 4.5 & 4.7 & 5.1 & 4.7 & 0.2 & $4.5 \pm 1.1$ \\
\hline PCB 151 & 29.4 & 28.6 & 28.1 & 29.1 & 28.8 & 0.6 & $28.6 \pm 1.3$ \\
\hline PCB 149 & 90.5 & 87.2 & 88.1 & 86.0 & 88.0 & 1.9 & $89.0 \pm 6.9$ \\
\hline PCB 118 & 77.1 & 73.8 & 76.5 & 77.4 & 76.2 & 1.6 & $76.5 \pm 2.9$ \\
\hline PCB 146 & 46.0 & 44.8 & 44.1 & 45.5 & 45.1 & 0.8 & $45.1 \pm 4.0$ \\
\hline PCB 153/132 & 257 & 258 & 258 & 239 & 253 & 9.3 & 249 \\
\hline PCB 105 & 28.4 & 28.8 & 28.2 & 28.0 & 28.4 & 0.3 & $28.6 \pm 1.2$ \\
\hline PCB 176 & 6.6 & 6.2 & 6.0 & 6.4 & 6.3 & 0.2 & $6.2 \pm 1.0$ \\
\hline PCB 137 & 7.76 & 7.55 & 7.18 & 7.7 & 7.55 & 0.3 & $7.7 \pm 1.4$ \\
\hline PCB 138/163 & 200 & 179 & 181 & 196 & 189 & 11 & 193 \\
\hline PCB 158 & 9.8 & 8.8 & 9.0 & 9.1 & 9.2 & 0.4 & $9.1 \pm 1.0$ \\
\hline PCB 178/175 & 28.7 & 24.2 & 23.4 & 25.4 & 25.4 & 2.3 & 25 \\
\hline PCB 187 & 115 & 124 & 128 & 125 & 123 & 5.6 & $121 \pm 11$ \\
\hline PCB 183 & 40.8 & 34.6 & 38.0 & 38.7 & 38.0 & 2.6 & $38.0 \pm 1.8$ \\
\hline PCB 128 & 23.5 & 21.6 & 23.4 & 23.9 & 23.1 & 1.0 & $23.0 \pm 1.1$ \\
\hline PCB 185 & 3.20 & 3.68 & 3.58 & 3.61 & 3.52 & 0.2 & $3.40 \pm 0.32$ \\
\hline PCB 174 & 25.8 & 25.8 & 24.8 & 25.4 & 25.5 & 0.5 & $25.2 \pm 0.1$ \\
\hline PCB 202 & 29.3 & 26.9 & 29.2 & 28.9 & 28.6 & 1.1 & $29.0 \pm 7.0$ \\
\hline PCB 177 & 29.1 & 27.3 & 29.1 & 28.9 & 28.6 & 0.9 & $28.6 \pm 1.2$ \\
\hline PCB 201 & 18.0 & 17.3 & 17.6 & 17.6 & 17.6 & 0.3 & $16.8 \pm 1.3$ \\
\hline PCB 156 & 11.9 & 11.3 & 11.3 & 11.7 & 11.6 & 0.3 & $11.4 \pm 0.9$ \\
\hline PCB 172 & 12.3 & 11.8 & 12.4 & 12.1 & 12.2 & 0.3 & $12.4 \pm 3.4$ \\
\hline PCB 157 & 3.4 & 3.4 & 3.0 & 3.4 & 3.3 & 0.2 & $3.27 \pm 0.67$ \\
\hline PCB 180/193 & 147 & 149 & 145 & 152 & 148 & 3.0 & 147 \\
\hline PCB 200 & 4.2 & 4.8 & 4.3 & 4.4 & 4.4 & 0.2 & $4.30 \pm 0.32$ \\
\hline PCB 191 & 1.8 & 1.6 & 1.6 & 1.4 & 1.6 & 0.2 & $1.57 \pm 0.45$ \\
\hline PCB 170 & 45.5 & 44.4 & 41.8 & 41.8 & 43.4 & 1.9 & $42.6 \pm 2.2$ \\
\hline PCB 199 & 85.4 & 87.9 & 80.9 & 85.9 & 85.0 & 3.0 & $84.2 \pm 8.0$ \\
\hline PCB 196 & 70.4 & 80.1 & 72.9 & 72.7 & 74.0 & 4.2 & $74.5 \pm 8.4$ \\
\hline PCB 208 & 22.1 & 21.9 & 23.6 & 24.6 & 23.1 & 1.3 & $23.9 \pm 1.7$ \\
\hline PCB 207 & 14.4 & 13.3 & 14.2 & 13.5 & 13.9 & 0.5 & $14.5 \pm 2.4$ \\
\hline PCB 195 & 13.9 & 13.5 & 14.5 & 14.8 & 14.2 & 0.6 & $14.3 \pm 2.2$ \\
\hline PCB 194 & 60.3 & 56.8 & 54.9 & 49.9 & 55.5 & 4.3 & $53.5 \pm 5.2$ \\
\hline PCB 206 & 43.9 & 43.4 & 46.2 & 41.1 & 43.7 & 2.1 & $44.9 \pm 4.2$ \\
\hline PCB 209 & 17.4 & 17.4 & 16.9 & 16.8 & 17.1 & 0.3 & $17.2 \pm 1.9$ \\
\hline
\end{tabular}


Table 9: Mass fractions of polychlorinated biphenyl congeners ( $\mathrm{ng} / \mathrm{g}$ wet mass) in northern fur seal blubber

\begin{tabular}{|c|c|c|c|c|c|c|c|c|c|c|c|c|c|}
\hline FRSL- & Storage ID & PCB 8 & PCB 18 & PCB $31 / 28$ & PCB 52 & PCB 49 & РCB 44 & РСB 95 & РCB 121 & PCB 74 & РCB 66 & РСB 92 & PCB 56 \\
\hline 1 & MM1B004 & 1.89 & 3.53 & 10.9 & 29.6 & 4.94 & 14.1 & 33.4 & 1.68 & 43.6 & 21.8 & 23.0 & 2.48 \\
\hline 2 & MM1B008 & $<1$ & 2.75 & 7.73 & 17.3 & 3.95 & 10.8 & 17.1 & $<1.2$ & 23.7 & 12.0 & 11.9 & 1.66 \\
\hline 3 & MM1B012 & $<1$ & 3.20 & 11.1 & 21.1 & 4.68 & 12.8 & 14.6 & $<1.2$ & 28.0 & 15.8 & 15.1 & 1.45 \\
\hline 4 & MM1B016 & 6.34 & 13.0 & 20.2 & 41.2 & 7.58 & 21.2 & 41.6 & 2.23 & 34.8 & 29.7 & 18.7 & 6.58 \\
\hline 5 & MM1B020 & 5.22 & 5.53 & 7.52 & 21.8 & 3.94 & 13.9 & 19.1 & $<0.26$ & 22.9 & 20.6 & 10.4 & 3.64 \\
\hline 6 & MM4B097 & 1.39 & 2.89 & 7.21 & 21.0 & 4.22 & 12.0 & 20.7 & $<1.2$ & 29.6 & 14.5 & 16.8 & 1.95 \\
\hline 7 & MM4B100 & $<1$ & 2.82 & 8.17 & 20.7 & 3.98 & 12.1 & 19.8 & $<1.2$ & 28.6 & 14.0 & 17.4 & 1.87 \\
\hline 8 & MM4B103 & $<1$ & 4.18 & 11.0 & 29.3 & 4.11 & 13.5 & 36.3 & $<1.2$ & 42.5 & 21.3 & 22.7 & 1.90 \\
\hline 9 & MM4B106 & $<1$ & 2.59 & 8.00 & 24.7 & 3.39 & 11.1 & 25.9 & $<1.2$ & 35.3 & 17.3 & 23.5 & 2.06 \\
\hline 10 & MM4B109 & 1.49 & 2.46 & 14.2 & 33.8 & 4.99 & 16.1 & 38.9 & $<1.2$ & 58.8 & 28.4 & 28.0 & 2.05 \\
\hline 11 & MM4B112 & $<1$ & 3.65 & 9.77 & 32.5 & 3.73 & 12.4 & 39.4 & $<1.2$ & 48.7 & 25.2 & 26.5 & 1.98 \\
\hline 12 & MM4B115 & $<1$ & 3.13 & 13.0 & 29.3 & 4.64 & 14.4 & 32.1 & $<1.2$ & 50.1 & 26.2 & 25.2 & 1.78 \\
\hline 13 & MM4B118 & $<1$ & 5.10 & 9.68 & 41.7 & 5.62 & 16.8 & 34.5 & $<1.2$ & 35.3 & 17.9 & 27.2 & 2.13 \\
\hline 14 & MM4B121 & $<1$ & 1.73 & 9.18 & 26.3 & 4.05 & 12.0 & 30.3 & $<1.2$ & 39.7 & 19.9 & 28.3 & 2.22 \\
\hline 15 & MM4B124 & 1.47 & 2.76 & 10.5 & 21.5 & 3.91 & 11.9 & 23.3 & $<1.2$ & 38.8 & 20.5 & 19.2 & 1.95 \\
\hline 16 & MM12B648 & $<1$ & 2.19 & 8.74 & 19.5 & 2.99 & 10.6 & 31.9 & $<1.2$ & 40.7 & 19.4 & 19.2 & 2.07 \\
\hline 17 & MM12B652 & $<1$ & 1.79 & 5.24 & 17.0 & 3.40 & 8.37 & 17.8 & 1.35 & 25.2 & 12.5 & 16.2 & 1.99 \\
\hline 18 & MM12B656 & $<1$ & 3.46 & 12.4 & 26.5 & 4.22 & 13.4 & 20.7 & 1.41 & 37.6 & 17.1 & 18.4 & 1.74 \\
\hline 19 & MM12B660 & $<1$ & 3.17 & 8.98 & 20.8 & 3.89 & 10.8 & 21.2 & $<1.2$ & 33.6 & 15.0 & 15.4 & 1.90 \\
\hline 20 & MM12B664 & $<1$ & 2.49 & 5.96 & 17.3 & 3.29 & 9.85 & 16.9 & 1.41 & 28.9 & 13.5 & 13.0 & 1.89 \\
\hline 22 & MM16B169 & 0.55 & 3.76 & 3.27 & 34.1 & 7.41 & 7.94 & 38.1 & $<0.26$ & 30.5 & 20.3 & 22.9 & 3.20 \\
\hline 23 & MM16B172 & 5.78 & 25.1 & 20.2 & 13.4 & 8.36 & 9.29 & 34.5 & 3.44 & 20.2 & 29.7 & 18.8 & 6.99 \\
\hline 24 & MM16B175 & 2.78 & $<0.58$ & 7.63 & 21.6 & 2.69 & 11.1 & 23.4 & $<0.26$ & 41.3 & 33.0 & 12.9 & 2.38 \\
\hline 25 & MM16B178 & 3.08 & 3.04 & 6.16 & 26.1 & 5.06 & 5.50 & 35.6 & $<0.26$ & 37.0 & 22.5 & 19.4 & $<0.55$ \\
\hline 26 & MM16B181 & 5.16 & 2.67 & 3.34 & 19.4 & 3.82 & 3.84 & 27.9 & $<0.26$ & 45.9 & 30.0 & 15.8 & $<0.55$ \\
\hline 27 & MM16B184 & 14.9 & 17.5 & 18.2 & 132 & 15.4 & 4.41 & 23.7 & $<0.26$ & 28.4 & 15.2 & 12.3 & $<0.55$ \\
\hline 28 & MM16B187 & 1.55 & 1.96 & 5.75 & 12.2 & 2.85 & 7.53 & 11.7 & 1.39 & 22.9 & 10.6 & 10.5 & 1.93 \\
\hline 29 & MM16B190 & 2.26 & 4.37 & 3.10 & 30.7 & 8.80 & 9.48 & 41.4 & $<0.26$ & 34.4 & 39.6 & 26.3 & 6.42 \\
\hline 30 & MM16B193 & 2.84 & 2.57 & 3.49 & 11.2 & 7.27 & 16.9 & 16.2 & $<0.26$ & 30.7 & 21.4 & 9.58 & $<0.55$ \\
\hline 31 & MM16B196 & 11.4 & 12.9 & 14.0 & 18.6 & 6.25 & 7.15 & 31.6 & $<0.26$ & 29.4 & 24.1 & 9.81 & $<0.55$ \\
\hline 38 & MM22B819 & $<0.88$ & 3.51 & 13.4 & 50.8 & 22.7 & 23.7 & 9.36 & 1.27 & 76.5 & 58.6 & 6.28 & $<0.55$ \\
\hline 39 & MM22B822 & 2.85 & 4.54 & 9.95 & 15.6 & 7.74 & 17.6 & 14.5 & $<0.26$ & 19.2 & 20.7 & 8.01 & $<0.55$ \\
\hline 40 & MM22B825 & 4.44 & 8.28 & 8.78 & 17.2 & 6.17 & 16.0 & 18.5 & $<0.26$ & 20.9 & 22.9 & 13.3 & $<0.55$ \\
\hline 41 & MM22B828 & $<1$ & 2.34 & 5.87 & 9.76 & 2.87 & 7.76 & 9.18 & $<1.2$ & 18.5 & 9.17 & 8.05 & 1.99 \\
\hline 42 & MM22B831 & 7.75 & 12.3 & 15.3 & 32.6 & 7.49 & 18.9 & 9.24 & $<0.26$ & 33.1 & 30.3 & 6.67 & $<0.55$ \\
\hline 44 & MM22B796 & 17.7 & 10.4 & 7.20 & 7.5 & 5.43 & 6.34 & 11.5 & 2.41 & 17.9 & 28.7 & 13.7 & 7.25 \\
\hline 45 & MM22B799 & 12.8 & 11.7 & 13.4 & 21.3 & 5.83 & 11.8 & 28.6 & $<0.26$ & 24.2 & 24.5 & 14.9 & $<0.55$ \\
\hline 46 & MM22B808 & $<1$ & 3.08 & 9.08 & 32.6 & 7.92 & 16.6 & 42.2 & $<1.2$ & 27.0 & 20.2 & 22.3 & 3.20 \\
\hline 47 & MM22B802 & 2.26 & 2.39 & 4.08 & 17.6 & 4.98 & 7.00 & 17.7 & $<0.26$ & 32.1 & 24.1 & 9.96 & $<0.55$ \\
\hline 48 & MM22B836 & 1.84 & 8.22 & 4.58 & 56.2 & 10.6 & 30.9 & 13.5 & $<0.26$ & 45.3 & 48.4 & 9.65 & $<0.55$ \\
\hline 52 & MM22B899 & 2.70 & 3.45 & 8.23 & 19.9 & 2.58 & 12.1 & 24.5 & $<0.26$ & 22.1 & 17.7 & 14.6 & $<0.55$ \\
\hline 53 & MM22B902 & 1.57 & 2.76 & 9.65 & 25.7 & 6.69 & 6.78 & 31.7 & $<0.26$ & 20.1 & 19.6 & 19.2 & 1.98 \\
\hline 54 & MM22B905 & $<1$ & 2.21 & 7.93 & 14.4 & 3.48 & 9.42 & 15.2 & $<1.2$ & 25.9 & 13.2 & 12.9 & 2.17 \\
\hline 55 & MM22B908 & $<1$ & 1.92 & 14.5 & 14.6 & 2.62 & 7.77 & 14.6 & 1.49 & 39.4 & 18.4 & 17.7 & 1.42 \\
\hline 56 & MM22B911 & $<1$ & 2.08 & 7.10 & 10.4 & 2.85 & 7.75 & 9.51 & $<1.2$ & 20.9 & 9.64 & 8.67 & 1.99 \\
\hline 57 & MM22B914 & $<1$ & 2.11 & 8.74 & 12.5 & 2.60 & 7.61 & 12.7 & 1.37 & 26.5 & 12.4 & 10.9 & 2.01 \\
\hline 58 & MM22B917 & $<1$ & 2.15 & 7.94 & 11.4 & 3.01 & 7.71 & 10.7 & $<1.2$ & 24.4 & 11.7 & 8.9 & 2.00 \\
\hline 59 & MM22B920 & $<1$ & 2.48 & 12.3 & 23.2 & 4.01 & 11.1 & 17.1 & $<1.2$ & 32.7 & 16.5 & 16.6 & 2.07 \\
\hline 60 & MM22B923 & $<1$ & 2.23 & 16.9 & 27.5 & 3.80 & 12.3 & 23.9 & 1.73 & 51.1 & 27.2 & 24.5 & 2.52 \\
\hline 61 & MM22B926 & $<1$ & 2.91 & 19.6 & 45.3 & 3.87 & 15.1 & 27.4 & 1.19 & 70.3 & 36.1 & 32.0 & 2.07 \\
\hline
\end{tabular}


Table 9 (cont.): Mass fractions of polychlorinated biphenyl congeners (ng/g wet mass) in northern fur seal blubber

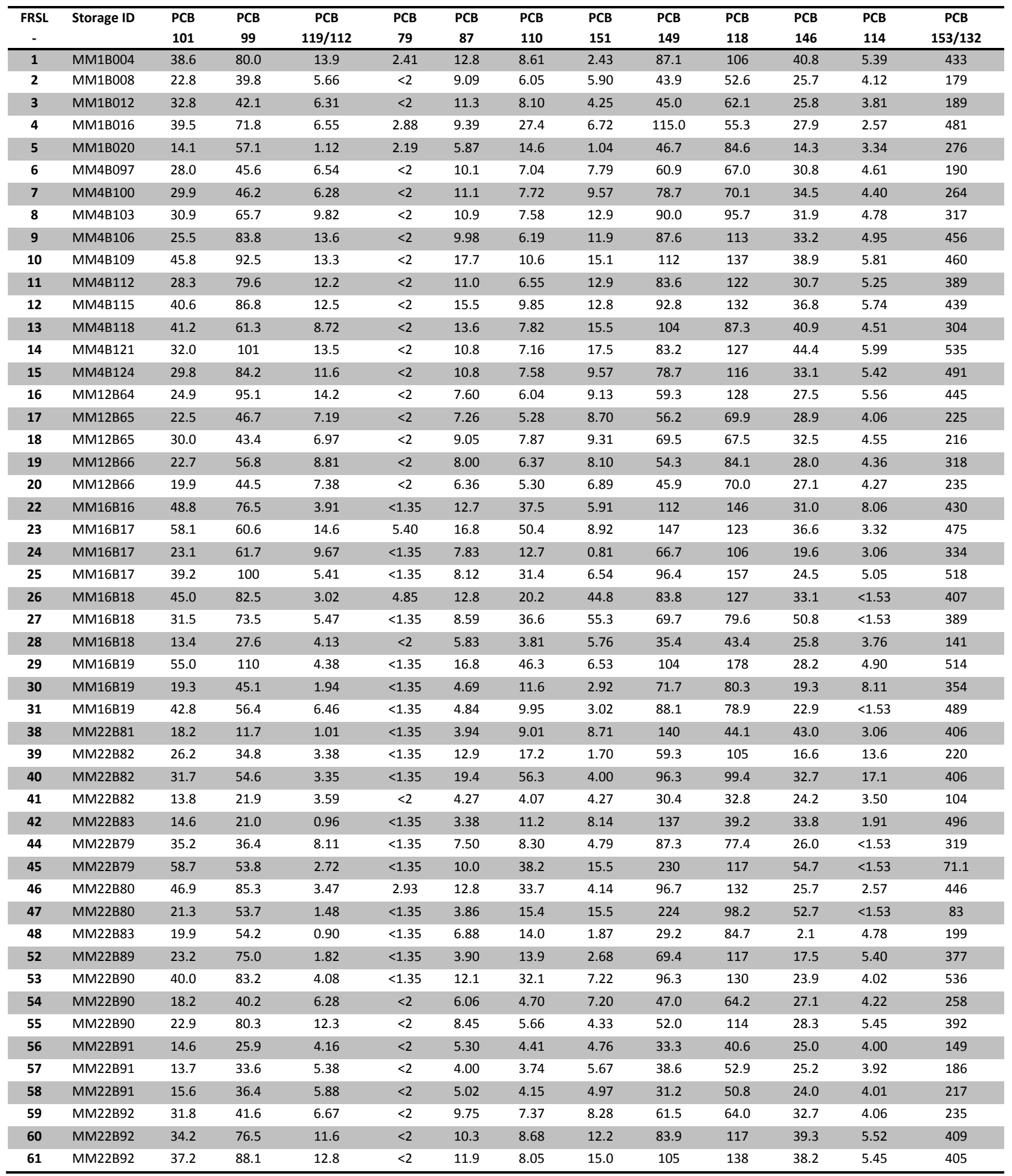


Table 9 (cont.): Mass fractions of polychlorinated biphenyl congeners (ng/g wet mass) in northern fur seal blubber

\begin{tabular}{|c|c|c|c|c|c|c|c|c|c|c|c|c|c|}
\hline $\begin{array}{c}\text { FRSL } \\
-\end{array}$ & Storage ID & $\begin{array}{l}\text { PCB } \\
105\end{array}$ & $\begin{array}{l}\text { PCB } \\
176\end{array}$ & $\begin{array}{l}\text { PCB } \\
127\end{array}$ & $\begin{array}{l}\text { PCB } \\
137\end{array}$ & $\begin{array}{c}\text { PCB } \\
138 / 163\end{array}$ & $\begin{array}{l}\text { PCB } \\
158\end{array}$ & $\begin{array}{c}\text { PCB } \\
178 / 175\end{array}$ & $\begin{array}{l}\text { PCB } \\
197\end{array}$ & $\begin{array}{l}\text { PCB } \\
187\end{array}$ & $\begin{array}{l}\text { PCB } \\
183\end{array}$ & $\begin{array}{l}\text { PCB } \\
159\end{array}$ & $\begin{array}{l}\text { PCB } \\
128\end{array}$ \\
\hline 1 & MM1B004 & 43.5 & 4.49 & 2.88 & 14.6 & 215 & 15.4 & 8.54 & 5.57 & 61.9 & 38.4 & 3.27 & 31.5 \\
\hline 2 & MM1B008 & 21.9 & 2.78 & $<2$ & 7.29 & 88.8 & 7.52 & 6.48 & 1.41 & 33.6 & 17.2 & 2.70 & 13.7 \\
\hline 3 & MM1B012 & 24.0 & 2.43 & $<2$ & 7.15 & 93.8 & 7.76 & 6.04 & 1.90 & 39.8 & 17.1 & 2.47 & 13.9 \\
\hline 4 & MM1B016 & 20.6 & 5.39 & $<0.39$ & 13.2 & 291 & 29.3 & 5.09 & $<0.51$ & 44.3 & 23.6 & $<0.82$ & 28.9 \\
\hline 5 & MM1B020 & 14.1 & $<0.23$ & $<0.39$ & 8.36 & 171 & 10.1 & 3.92 & $<0.51$ & 79.3 & 62.4 & $<0.82$ & 19.9 \\
\hline 6 & MM4B097 & 26.7 & 3.13 & 2.35 & 8.05 & 101 & 8.47 & 6.91 & 0.95 & 44.9 & 22.1 & 2.85 & 15.9 \\
\hline 7 & MM4B100 & 26.3 & 3.36 & 2.40 & 9.85 & 132 & 9.34 & 6.99 & 3.38 & 61.8 & 30.7 & 2.77 & 19.1 \\
\hline 8 & MM4B103 & 35.8 & 3.85 & 2.02 & 11.3 & 160 & 10.9 & 7.11 & 4.70 & 62.3 & 34.9 & 2.68 & 22.5 \\
\hline 9 & MM4B106 & 44.3 & 3.83 & 2.36 & 14.3 & 227 & 14.7 & 7.75 & 5.24 & 66.3 & 38.6 & 2.94 & 29.8 \\
\hline 10 & MM4B109 & 51.5 & 4.19 & 2.65 & 15.3 & 226 & 14.8 & 8.24 & 4.32 & 77.2 & 44.0 & 2.99 & 31.3 \\
\hline 11 & MM4B112 & 44.4 & 4.21 & 2.50 & 12.7 & 189 & 12.5 & 8.00 & 4.44 & 57.6 & 42.9 & 2.87 & 25.2 \\
\hline 12 & MM4B115 & 46.5 & 3.54 & 2.58 & 14.6 & 217 & 13.8 & 7.22 & 5.41 & 64.7 & 38.7 & 3.01 & 28.5 \\
\hline 13 & MM4B118 & 33.0 & 4.14 & 2.69 & 11.0 & 155 & 10.6 & 7.85 & 2.97 & 83.2 & 37.2 & 2.79 & 20.8 \\
\hline 15 & MM4B124 & 44.1 & 3.36 & 2.79 & 16.5 & 244 & 15.7 & 8.36 & 6.45 & 58.6 & 32.9 & 3.32 & 33.8 \\
\hline 16 & MM12B64 & 45.8 & 3.68 & 2.57 & 14.6 & 208 & 13.1 & 8.03 & 5.40 & 46.4 & 29.6 & 3.01 & 27.7 \\
\hline 17 & MM12B65 & 25.9 & 2.93 & 2.35 & 8.07 & 146 & 8.86 & 6.83 & 2.13 & 42.0 & 23.3 & 2.68 & 17.1 \\
\hline 18 & MM12B65 & 23.4 & 3.22 & 2.29 & 8.23 & 103 & 7.94 & 6.79 & 2.18 & 54.9 & 27.8 & 2.69 & 15.6 \\
\hline 19 & MM12B66 & 29.9 & 3.27 & 2.27 & 10.6 & 147 & 10.6 & 7.24 & 5.59 & 45.2 & 26.4 & 2.89 & 21.6 \\
\hline 20 & MM12B66 & 25.1 & 3.09 & $<2$ & 8.92 & 113 & 8.83 & 6.72 & 1.19 & 37.8 & 20.8 & 2.64 & 18.0 \\
\hline 22 & MM16B16 & 36.1 & 10.0 & $<0.39$ & 11.7 & 263 & 11.2 & 5.25 & $<0.51$ & 88.5 & 50.4 & $<0.82$ & 23.6 \\
\hline 23 & MM16B17 & 33.1 & 3.42 & $<0.39$ & 7.87 & 271 & 27.7 & 9.66 & $<0.51$ & 38.2 & 20.6 & $<0.82$ & 17.7 \\
\hline 24 & MM16B17 & 25.6 & $<0.23$ & $<0.39$ & 7.00 & 194 & 12.4 & 9.04 & $<0.51$ & 51.4 & 40.1 & $<0.82$ & 18.7 \\
\hline 25 & MM16B17 & 9.01 & 5.05 & $<0.39$ & 16.6 & 316 & 31.1 & 17.6 & $<0.51$ & 44.8 & 33.5 & $<0.82$ & 32.5 \\
\hline 26 & MM16B18 & 27.3 & 6.00 & $<0.39$ & 1.40 & 261 & 1.48 & 1.68 & $<0.51$ & 50.1 & 39.2 & $<0.82$ & 25.7 \\
\hline 27 & MM16B18 & 25.7 & $<0.23$ & $<0.39$ & 22.1 & 400 & 13.1 & 11.5 & $<0.51$ & 58.4 & 49.2 & $<0.82$ & 21.5 \\
\hline 28 & MM16B18 & 16.8 & 2.95 & $<2$ & 6.25 & 66.8 & 6.6 & 6.46 & 1.00 & 35.6 & 17.8 & 2.74 & 11.5 \\
\hline 31 & MM16B19 & 23.6 & $<0.23$ & $<0.39$ & 8.86 & 273 & 11.1 & 5.99 & $<0.51$ & 35.3 & 22.1 & $<0.82$ & 19.0 \\
\hline 38 & MM22B81 & 12.6 & $<0.23$ & $<0.39$ & 36.9 & 222 & 28.6 & 15.9 & $<0.51$ & 53.5 & 24.7 & $<0.82$ & 14.9 \\
\hline 39 & MM22B82 & 20.1 & $<0.23$ & $<0.39$ & 32.0 & 121 & 10.1 & 12.1 & $<0.51$ & 51.1 & 43.2 & $<0.82$ & 10.7 \\
\hline 40 & MM22B82 & 28.3 & 7.35 & $<0.39$ & 11.8 & 236 & 23.2 & 17.2 & $<0.51$ & 62.5 & 35.0 & $<0.82$ & 25.4 \\
\hline 41 & MM22B82 & 13.2 & 2.80 & $<2$ & 5.02 & 49.7 & 5.22 & 6.75 & 0.70 & 32.9 & 15.5 & 2.62 & 9.06 \\
\hline 42 & MM22B83 & 5.25 & 14.8 & $<0.39$ & 61.8 & 296 & 18.5 & 25.8 & $<0.51$ & 115 & 58.0 & $<0.82$ & 21.0 \\
\hline 44 & MM22B79 & 19.0 & 4.56 & $<0.39$ & 8.90 & 183 & 23.1 & 11.3 & $<0.51$ & 51.9 & 26.3 & $<0.82$ & 16.7 \\
\hline 45 & MM22B79 & 33.9 & 4.24 & $<0.39$ & 9.08 & 386 & 36.4 & 88.2 & $<0.51$ & 44.8 & 18.7 & $<0.82$ & 18.7 \\
\hline 46 & MM22B80 & 35.3 & 15.4 & $<2$ & 32.5 & 253 & 20.9 & 34.6 & 0.56 & 114 & 77.4 & $<2$ & 22.5 \\
\hline 47 & MM22B80 & 27.8 & 8.19 & $<0.39$ & 5.82 & 325 & 20.7 & 24.1 & $<0.51$ & 77.6 & 51.2 & $<0.82$ & 11.1 \\
\hline 48 & MM22B83 & 17.7 & $<0.23$ & $<0.39$ & 18.2 & 116 & 2.48 & 30.5 & $<0.51$ & 169 & 99.7 & $<0.82$ & 2.26 \\
\hline 52 & MM22B89 & 32.4 & 8.53 & $<0.39$ & 28.7 & 216 & 11.1 & 16.0 & $<0.51$ & 65.8 & 27.7 & $<0.82$ & 20.7 \\
\hline 53 & MM22B90 & 32.6 & 0.61 & $<0.39$ & 38.3 & 293 & 24.1 & 4.92 & $<0.51$ & 8.08 & 6.42 & $<0.82$ & 10.8 \\
\hline 54 & MM22B90 & 22.8 & 3.12 & $<2$ & 8.12 & 106 & 8.58 & 7.33 & 3.29 & 41.2 & 25.3 & 2.84 & 16.8 \\
\hline 55 & MM22B90 & 38.2 & 2.80 & 2.53 & 12.2 & 178 & 11.5 & 7.29 & 4.36 & 50.7 & 20.1 & 2.92 & 23.6 \\
\hline 56 & MM22B91 & 15.5 & 3.14 & $<2$ & 6.12 & 66.7 & 6.83 & 6.73 & 1.97 & 36.6 & 15.4 & 2.62 & 12.3 \\
\hline 57 & MM22B91 & 19.5 & 2.96 & 2.21 & 7.18 & 86.9 & 7.09 & 6.52 & 2.70 & 36.3 & 20.7 & 2.61 & 13.9 \\
\hline 58 & MM22B91 & 18.5 & 2.87 & $<2$ & 7.69 & 96.2 & 7.57 & 7.05 & 1.78 & 36.6 & 16.4 & 2.76 & 14.7 \\
\hline 59 & MM22B92 & 21.4 & 3.43 & 2.19 & 8.16 & 104 & 7.81 & 6.36 & 2.31 & 58.8 & 23.4 & 2.58 & 15.3 \\
\hline 60 & MM22B92 & 39.8 & 3.80 & 2.70 & 12.7 & 185 & 12.9 & 8.70 & 5.07 & 72.5 & 36.7 & 3.03 & 24.5 \\
\hline 61 & MM22B92 & 48.9 & 3.62 & $<2$ & 12.6 & 200 & 12.6 & 6.65 & 4.32 & 72.0 & 38.2 & 2.49 & 27.8 \\
\hline
\end{tabular}


Table 9 (cont.): Mass fractions of polychlorinated biphenyl congeners ( $\mathrm{ng} / \mathrm{g}$ wet mass) in northern fur seal blubber

\begin{tabular}{|c|c|c|c|c|c|c|c|c|c|c|c|c|c|}
\hline $\begin{array}{c}\text { FRSL } \\
-\end{array}$ & Storage ID & $\begin{array}{l}\text { PCB } \\
185\end{array}$ & $\begin{array}{l}\text { PCB } \\
174\end{array}$ & $\begin{array}{l}\text { PCB } \\
167\end{array}$ & $\begin{array}{l}\text { PCB } \\
202\end{array}$ & $\begin{array}{l}\text { PCB } \\
177\end{array}$ & $\begin{array}{l}\text { PCB } \\
201\end{array}$ & $\begin{array}{l}\text { PCB } \\
156\end{array}$ & $\begin{array}{l}\text { PCB } \\
172\end{array}$ & $\begin{array}{l}\text { PCB } \\
157\end{array}$ & $\begin{array}{c}\text { PCB } \\
180 / 193\end{array}$ & $\begin{array}{l}\text { PCB } \\
200\end{array}$ & $\begin{array}{l}\text { PCB } \\
170\end{array}$ \\
\hline 1 & MM1B004 & 16.9 & 5.24 & 9.06 & $<2$ & 6.15 & 2.30 & 11.83 & 5.20 & 5.66 & 219 & 3.28 & 44.1 \\
\hline 2 & MM1B008 & 13.1 & 2.71 & 3.98 & $<2$ & 3.97 & $<1$ & 4.73 & 3.10 & 3.32 & 71.6 & $<1.5$ & 15.0 \\
\hline 3 & MM1B012 & 13.5 & 2.90 & 4.43 & 3.03 & 3.94 & $<1$ & 4.89 & 3.30 & 3.30 & 81.1 & $<1.5$ & 16.5 \\
\hline 4 & MM1B016 & 3.73 & 2.64 & 12.4 & 10.2 & 10.5 & 7.39 & 17.8 & 8.85 & 12.2 & 64.4 & 2.66 & 4.43 \\
\hline 5 & MM1B020 & $<0.45$ & 2.32 & 5.62 & $<1.86$ & $<0.28$ & $<0.51$ & 11.3 & $<0.30$ & $<1.37$ & 30.5 & $<1.75$ & 7.79 \\
\hline 6 & MM4B097 & 12.8 & 4.18 & 5.54 & 3.03 & 5.33 & $<1$ & 6.31 & 4.02 & 3.93 & 73.5 & $<1.5$ & 16.7 \\
\hline 7 & MM4B100 & 20.3 & 5.48 & 5.61 & 3.66 & 6.35 & 1.40 & 6.07 & 4.35 & 4.10 & 131 & $<1.5$ & 26.0 \\
\hline 8 & MM4B103 & 23.8 & 5.15 & 7.56 & 3.98 & 5.91 & 1.15 & 7.64 & 4.42 & 4.23 & 146 & 2.27 & 28.2 \\
\hline 9 & MM4B106 & 31.4 & 5.90 & 7.84 & 4.61 & 6.68 & 2.24 & 9.87 & 5.20 & 4.87 & 201 & $<1.5$ & 38.6 \\
\hline 10 & MM4B109 & 30.8 & 6.31 & 10.1 & 4.32 & 7.07 & 1.56 & 8.94 & 5.05 & 5.26 & 189 & $<1.5$ & 35.6 \\
\hline 11 & MM4B112 & 27.2 & 5.67 & 8.51 & $<2$ & 6.45 & $<1$ & 8.94 & 4.75 & 4.80 & 162 & $<1.5$ & 32.8 \\
\hline 12 & MM4B115 & 29.9 & 5.12 & 9.19 & 4.54 & 6.01 & 2.32 & 9.00 & 4.58 & 4.96 & 182 & $<1.5$ & 34.6 \\
\hline 13 & MM4B118 & 21.9 & 5.09 & 6.15 & 4.12 & 6.08 & $<1$ & 7.09 & 5.44 & 4.39 & 128 & $<1.5$ & 26.0 \\
\hline 15 & MM4B124 & 33.4 & 5.04 & 7.80 & 3.99 & 6.04 & $<1$ & 9.05 & 4.28 & 5.57 & 215 & $<1.5$ & 44.7 \\
\hline 16 & MM12B64 & 30.4 & 4.22 & 8.41 & 4.00 & 5.23 & 3.05 & 8.72 & 4.15 & 4.99 & 183 & $<1.5$ & 36.6 \\
\hline 17 & MM12B65 & 13.9 & 3.38 & 5.23 & 2.99 & 4.56 & $<1$ & 5.49 & 3.55 & 3.84 & 88.4 & $<1.5$ & 18.8 \\
\hline 18 & MM12B65 & 14.7 & 4.20 & 5.44 & 3.29 & 6.25 & $<1$ & 4.62 & 4.16 & 3.58 & 80.3 & $<1.5$ & 17.0 \\
\hline 19 & MM12B66 & 24.4 & 3.97 & 7.03 & 3.98 & 4.99 & 2.05 & 6.42 & 4.05 & 4.21 & 156 & $<1.5$ & 29.7 \\
\hline 20 & MM12B66 & 15.2 & 3.79 & 5.37 & $<2$ & 4.87 & $<1$ & 5.93 & 3.38 & 3.93 & 80.7 & $<1.5$ & 1.64 \\
\hline 22 & MM16B16 & 14.1 & 49.5 & 12.7 & 13.5 & 22.2 & 6.88 & 13.1 & 6.92 & $<1.37$ & 135 & 7.37 & 30.3 \\
\hline 23 & MM16B17 & 4.51 & 22.1 & 10.7 & 17.1 & 31.0 & 6.98 & 14.3 & 2.28 & 6.93 & 48.6 & $<1.75$ & 11.4 \\
\hline 24 & MM16B17 & $<0.45$ & 3.87 & 3.65 & $<1.86$ & $<0.28$ & $<0.51$ & 10.4 & $<0.30$ & $<1.37$ & 11.2 & $<1.75$ & 4.32 \\
\hline 25 & MM16B17 & $<0.45$ & 72.7 & 15.5 & 18.7 & 10.7 & 4.76 & 18.2 & 2.62 & $<1.37$ & 88.1 & 33.6 & 26.7 \\
\hline 26 & MM16B18 & 10.47 & 32.0 & 8.93 & 15.2 & $<0.28$ & $<0.51$ & 13.1 & $<0.30$ & 4.94 & 101 & $<1.75$ & 25.6 \\
\hline 27 & MM16B18 & $<0.45$ & 1.65 & 3.53 & $<1.86$ & $<0.28$ & $<0.51$ & 9.43 & $<0.30$ & $<1.37$ & 82.4 & $<1.75$ & 23.0 \\
\hline 28 & MM16B18 & 10.5 & 2.67 & 4.73 & $<2$ & 3.96 & $<1$ & 4.46 & 3.33 & 3.62 & 62.8 & $<1.5$ & 13.6 \\
\hline 31 & MM16B19 & $<0.45$ & 10.2 & 5.98 & $<1.86$ & $<0.28$ & $<0.51$ & 13.3 & $<0.30$ & $<1.37$ & 41.1 & $<1.75$ & 19.1 \\
\hline 38 & MM22B81 & 4.44 & 25.4 & 15.32 & 8.91 & 11.3 & 18.5 & 13.4 & $<0.30$ & $<1.37$ & 59.3 & $<1.75$ & 14.9 \\
\hline 39 & MM22B82 & 17.1 & 3.36 & 3.12 & $<1.86$ & $<0.28$ & $<0.51$ & 3.06 & $<0.30$ & $<1.37$ & 109 & $<1.75$ & 38.9 \\
\hline 40 & MM22B82 & $<0.45$ & 3.59 & 5.96 & $<1.86$ & $<0.28$ & $<0.51$ & 5.84 & $<0.30$ & $<1.37$ & 148 & $<1.75$ & 59.6 \\
\hline 41 & MM22B82 & 8.33 & 2.59 & 3.82 & $<2$ & 3.90 & $<1$ & 3.45 & 3.04 & 3.17 & 40.7 & $<1.5$ & 10.5 \\
\hline 42 & MM22B83 & $<0.45$ & 19.3 & 10.2 & $<1.86$ & 37.2 & 18.8 & 14.1 & $<0.30$ & $<1.37$ & 153 & 13.8 & 35.4 \\
\hline 44 & MM22B79 & $<0.45$ & 12.0 & 10.2 & 9.35 & 12.7 & 6.36 & 12.9 & 6.64 & 7.31 & 72.7 & $<1.75$ & 41.7 \\
\hline 45 & MM22B79 & $<0.45$ & 38.9 & 14.9 & 24.7 & 9.44 & 14.7 & 17.0 & 27.15 & 7.44 & 193 & 28.1 & 65.6 \\
\hline 46 & $\mathrm{MM} 22 \mathrm{~B} 80$ & 19.5 & 20.2 & 3.25 & 11.6 & 31.3 & 4.11 & 13.1 & 8.68 & 3.54 & 183 & $<1.5$ & 43.6 \\
\hline 47 & MM22B80 & $<0.45$ & 44.7 & 20.9 & 12.9 & 21.5 & 6.46 & 8.88 & 11.0 & $<1.37$ & 130 & $<1.75$ & 28.1 \\
\hline 48 & MM22B83 & $<0.45$ & 10.1 & 1.88 & $<1.86$ & $<0.28$ & $<0.51$ & 1.50 & $<0.30$ & $<1.37$ & 192 & $<1.75$ & 48.4 \\
\hline 52 & MM22B89 & $<0.45$ & 15.4 & 7.81 & 16.6 & 9.51 & 5.68 & 4.93 & $<0.30$ & $<1.37$ & 101 & $<1.75$ & 62.6 \\
\hline 53 & MM22B90 & 4.83 & 4.69 & 3.60 & 14.0 & 1.90 & 10.0 & 8.41 & $<0.30$ & $<1.37$ & 32.8 & $<1.75$ & 4.83 \\
\hline 54 & MM22B90 & 19.2 & 4.19 & 5.86 & 3.64 & 5.30 & $<1$ & 5.94 & 4.61 & 4.17 & 125 & $<1.5$ & 26.6 \\
\hline 55 & MM22B90 & 22.0 & 3.77 & 8.02 & 3.86 & 4.88 & $<1$ & 7.61 & 4.00 & 4.64 & 142 & $<1.5$ & 28.9 \\
\hline 56 & MM22B91 & 10.8 & 3.36 & 5.64 & $<2$ & 4.53 & $<1$ & 4.37 & 3.62 & 3.80 & 59.2 & $<1.5$ & 15.1 \\
\hline 57 & MM22B91 & 13.4 & 3.29 & 5.55 & $<2$ & 4.42 & $<1$ & 5.01 & 3.28 & 3.77 & 78.0 & $<1.5$ & 16.5 \\
\hline 58 & MM22B91 & 15.6 & 2.61 & 4.54 & $<2$ & 3.94 & $<1$ & 4.11 & 3.33 & 3.79 & 87.2 & $<1.5$ & 18.6 \\
\hline 59 & MM22B92 & 15.8 & 3.99 & 6.05 & $<2$ & 4.93 & $<1$ & 4.75 & 3.63 & 3.79 & 87.3 & $<1.5$ & 18.5 \\
\hline 60 & MM22B92 & 25.2 & 6.28 & 8.75 & 3.82 & 7.21 & $<1$ & 6.86 & 5.06 & 4.65 & 140 & $<1.5$ & 29.6 \\
\hline 61 & MM22B92 & 23.8 & 6.45 & 9.91 & 3.42 & 6.91 & 1.59 & 8.98 & 4.07 & 4.59 & 145 & $<1.5$ & 31.2 \\
\hline
\end{tabular}


Table 9 (cont.): Mass fractions of polychlorinated biphenyl congeners (ng/g wet mass) in northern fur seal blubber

\begin{tabular}{|c|c|c|c|c|c|c|c|c|c|c|c|}
\hline FRSL- & Storage ID & РCB 191 & РCB 199 & РCB 196 & PCB 208 & PCB 207 & PCB 195 & РCB 194 & PCB 205 & РCB 206 & PCB 209 \\
\hline 1 & MM1B004 & 1.92 & 16.0 & 19.1 & 4.32 & 2.19 & 4.73 & 13.5 & $<2.7$ & 4.52 & 5.33 \\
\hline 2 & MM1B008 & $<1$ & 5.34 & 8.86 & $<1$ & $<1.2$ & $<1.5$ & 5.82 & $<2.7$ & $<1$ & $<3.4$ \\
\hline 3 & MM1B012 & 1.27 & 6.51 & 9.82 & $<1$ & $<1.2$ & $<1.5$ & 6.38 & $<2.7$ & $<1$ & $<3.4$ \\
\hline 4 & MM1B016 & $<0.66$ & 17.5 & 10.1 & 3.32 & 5.75 & 13.4 & 26.8 & 4.44 & 2.99 & 6.65 \\
\hline 5 & MM1B020 & $<0.66$ & 13.5 & 5.42 & $<1.26$ & $<0.59$ & $<0.57$ & $<0.14$ & $<0.29$ & $<0.48$ & $<0.90$ \\
\hline 6 & MM4B097 & 0.97 & 6.55 & 9.75 & 1.77 & 1.67 & $<1.5$ & 5.50 & $<2.7$ & 1.75 & $<3.4$ \\
\hline 7 & MM4B100 & 1.74 & 10.6 & 12.6 & 2.49 & 1.80 & 2.76 & 8.29 & $<2.7$ & 2.56 & 4.71 \\
\hline 8 & MM4B103 & 1.78 & 11.7 & 14.0 & 2.48 & 1.78 & 3.12 & 9.36 & $<2.7$ & 3.79 & $<3.4$ \\
\hline 9 & MM4B106 & 1.26 & 14.2 & 15.9 & 2.82 & 1.61 & 3.53 & 9.96 & $<2.7$ & 3.00 & $<3.4$ \\
\hline 10 & MM4B109 & 1.41 & 12.1 & 13.5 & 1.96 & 2.04 & 3.39 & 9.39 & $<2.7$ & 2.71 & $<3.4$ \\
\hline 11 & MM4B112 & 1.18 & 11.7 & 13.0 & 2.14 & 1.90 & $<1.5$ & 8.98 & $<2.7$ & 2.50 & $<3.4$ \\
\hline 12 & MM4B115 & 1.68 & 12.7 & 16.2 & 3.53 & 2.62 & 1.93 & 9.00 & $<2.7$ & 3.44 & $<3.4$ \\
\hline 13 & MM4B118 & 1.52 & 8.82 & 12.3 & 2.61 & 2.16 & $<1.5$ & 7.56 & $<2.7$ & 2.39 & $<3.4$ \\
\hline 14 & MM4B121 & 1.89 & 19.2 & 21.4 & 3.90 & 2.78 & 5.05 & 13.9 & $<2.7$ & 4.97 & $<3.4$ \\
\hline 16 & MM12B648 & 2.07 & 12.3 & 15.8 & 3.76 & 2.86 & 3.18 & 10.3 & $<2.7$ & 4.05 & 5.94 \\
\hline 17 & MM12B652 & 1.25 & 7.24 & 10.5 & $<1$ & $<1.2$ & $<1.5$ & 4.20 & $<2.7$ & $<1$ & $<3.4$ \\
\hline 18 & MM12B656 & $<1$ & 6.79 & 10.5 & $<1$ & $<1.2$ & $<1.5$ & 6.35 & $<2.7$ & $<1$ & $<3.4$ \\
\hline 19 & MM12B660 & 1.55 & 14.4 & 17.3 & 4.15 & 2.64 & 4.47 & 12.9 & $<2.7$ & 3.60 & 6.34 \\
\hline 20 & MM12B664 & $<1$ & 6.09 & 11.1 & $<1$ & $<1.2$ & $<1.5$ & 5.83 & $<2.7$ & $<1$ & $<3.4$ \\
\hline 22 & MM16B169 & 1.05 & 16.2 & 34.6 & $<1.26$ & $<0.59$ & $<0.57$ & 10.1 & $<0.29$ & $<0.48$ & $<0.90$ \\
\hline 23 & MM16B172 & $<0.66$ & 33.2 & 34.6 & $<1.26$ & $<0.59$ & 6.10 & 15.3 & $<0.29$ & $<0.48$ & $<0.90$ \\
\hline 24 & MM16B175 & $<0.66$ & 7.85 & 5.06 & $<1.26$ & $<0.59$ & $<0.57$ & $<0.14$ & $<0.29$ & $<0.48$ & $<0.90$ \\
\hline 25 & MM16B178 & 11.78 & 34.8 & 47.5 & 2.86 & $<0.59$ & 11.0 & 14.5 & $<0.29$ & $<0.48$ & $<0.90$ \\
\hline 26 & MM16B181 & $<0.66$ & 16.8 & 18.4 & $<1.26$ & $<0.59$ & $<0.57$ & 6.44 & $<0.29$ & $<0.48$ & $<0.90$ \\
\hline 27 & MM16B184 & $<0.66$ & 13.9 & 15.9 & $<1.26$ & $<0.59$ & $<0.57$ & $<0.14$ & $<0.29$ & $<0.48$ & $<0.90$ \\
\hline 28 & MM16B187 & $<1$ & 6.77 & 9.98 & $<1$ & $<1.2$ & $<1.5$ & 7.74 & $<2.7$ & $<1$ & $<3.4$ \\
\hline 29 & MM16B190 & $<0.66$ & 18.3 & 22.0 & $<1.26$ & $<0.59$ & $<0.57$ & $<0.14$ & $<0.29$ & $<0.48$ & $<0.90$ \\
\hline 38 & MM22B819 & $<0.66$ & 19.5 & 18.6 & $<1.26$ & $<0.59$ & 10.8 & 11.4 & $<0.29$ & $<0.48$ & $<0.90$ \\
\hline 39 & MM22B822 & $<0.66$ & 14.1 & 13.4 & $<1.26$ & $<0.59$ & $<0.57$ & $<0.14$ & $<0.29$ & $<0.48$ & $<0.90$ \\
\hline 40 & MM22B825 & $<0.66$ & 46.5 & 40.0 & $<1.26$ & $<0.59$ & $<0.57$ & $<0.14$ & $<0.29$ & $<0.48$ & $<0.90$ \\
\hline 41 & MM22B828 & $<1$ & 6.29 & 5.53 & $<1$ & $<1.2$ & $<1.5$ & 1.45 & $<2.7$ & $<1$ & $<3.4$ \\
\hline 42 & MM22B831 & $<0.66$ & 17.9 & 23.6 & $<1.26$ & $<0.59$ & $<0.57$ & 23.4 & $<0.29$ & $<0.48$ & $<0.90$ \\
\hline 44 & MM22B796 & 7.47 & 18.2 & 15.8 & $<1.26$ & $<0.59$ & 7.78 & 11.9 & $<0.29$ & $<0.48$ & $<0.90$ \\
\hline 45 & MM22B799 & 11.17 & 53.7 & 28.2 & $<1.26$ & $<0.59$ & 11.4 & 36.5 & $<0.29$ & $<0.48$ & $<0.90$ \\
\hline 46 & MM22B808 & $<1$ & 20.6 & 21.8 & 1.20 & $<1.2$ & 1.56 & 6.54 & $<2.7$ & $<1$ & $<3.4$ \\
\hline 47 & MM22B802 & $<0.66$ & 16.6 & 21.4 & $<1.26$ & $<0.59$ & $<0.57$ & $<0.14$ & $<0.29$ & $<0.48$ & $<0.90$ \\
\hline 48 & MM22B836 & $<0.66$ & 19.9 & 15.3 & $<1.26$ & $<0.59$ & $<0.57$ & $<0.14$ & $<0.29$ & $<0.48$ & $<0.90$ \\
\hline 52 & MM22B899 & $<0.66$ & 52.7 & 51.1 & $<1.26$ & $<0.59$ & $<0.57$ & $<0.14$ & $<0.29$ & $<0.48$ & $<0.90$ \\
\hline 53 & MM22B902 & $<0.66$ & 26.1 & 29.5 & $<1.26$ & $<0.59$ & $<0.57$ & 11.90 & $<0.29$ & $<0.48$ & $<0.90$ \\
\hline 54 & MM22B905 & 1.44 & 12.8 & 15.0 & 2.72 & $<1.2$ & 4.15 & 8.63 & $<2.7$ & $<1$ & $<3.4$ \\
\hline 55 & MM22B908 & 1.51 & 10.1 & 12.8 & 3.07 & 2.33 & $<1.5$ & 8.14 & $<2.7$ & $<1$ & 4.51 \\
\hline 56 & MM22B911 & 1.81 & 7.22 & 9.23 & $<1$ & $<1.2$ & $<1.5$ & 6.74 & $<2.7$ & $<1$ & $<3.4$ \\
\hline 57 & MM22B914 & 0.94 & 9.05 & 11.8 & $<1$ & $<1.2$ & $<1.5$ & 7.46 & $<2.7$ & $<1$ & $<3.4$ \\
\hline 58 & MM22B917 & 1.48 & 7.05 & 10.3 & $<1$ & $<1.2$ & $<1.5$ & 7.77 & $<2.7$ & $<1$ & $<3.4$ \\
\hline 59 & MM22B920 & 1.95 & 6.88 & 11.9 & $<1$ & $<1.2$ & $<1.5$ & 7.48 & $<2.7$ & $<1$ & $<3.4$ \\
\hline 60 & MM22B923 & 1.12 & 10.0 & 13.7 & 2.20 & 2.19 & $<1.5$ & 7.21 & $<2.7$ & 3.21 & $<3.4$ \\
\hline 61 & MM22B926 & 1.46 & 12.3 & 12.4 & 1.99 & 1.58 & $<1.5$ & 7.31 & $<2.7$ & 1.72 & $<3.4$ \\
\hline
\end{tabular}


Table 10: Mass fractions of chlorinated pesticides ( $\mathrm{ng} / \mathrm{g}$ wet mass) in northern fur seal blubber

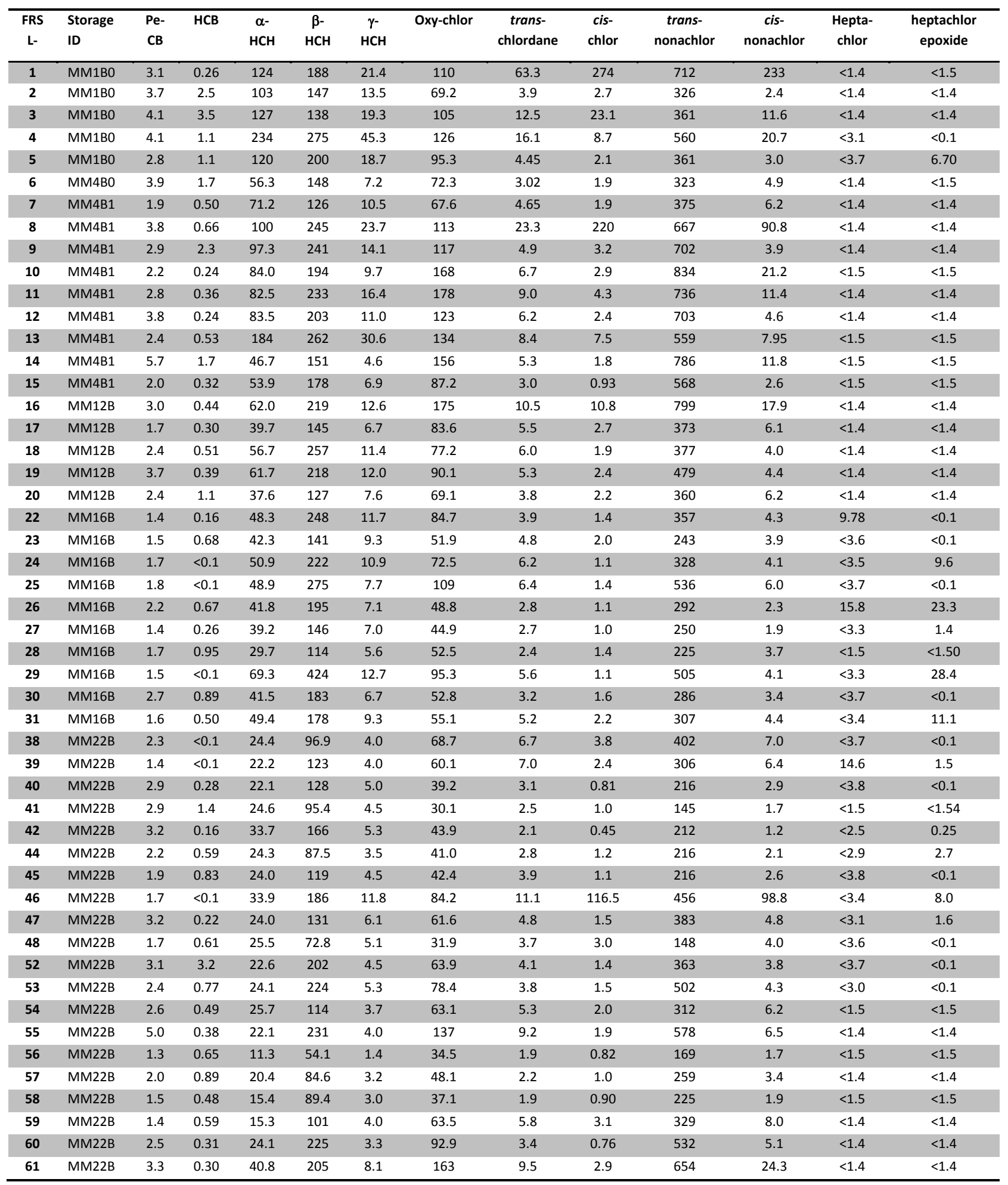


Table 10 (cont.): Mass fractions of chlorinated pesticides ( $\mathrm{ng} / \mathrm{g}$ wet mass) in northern fur seal blubber

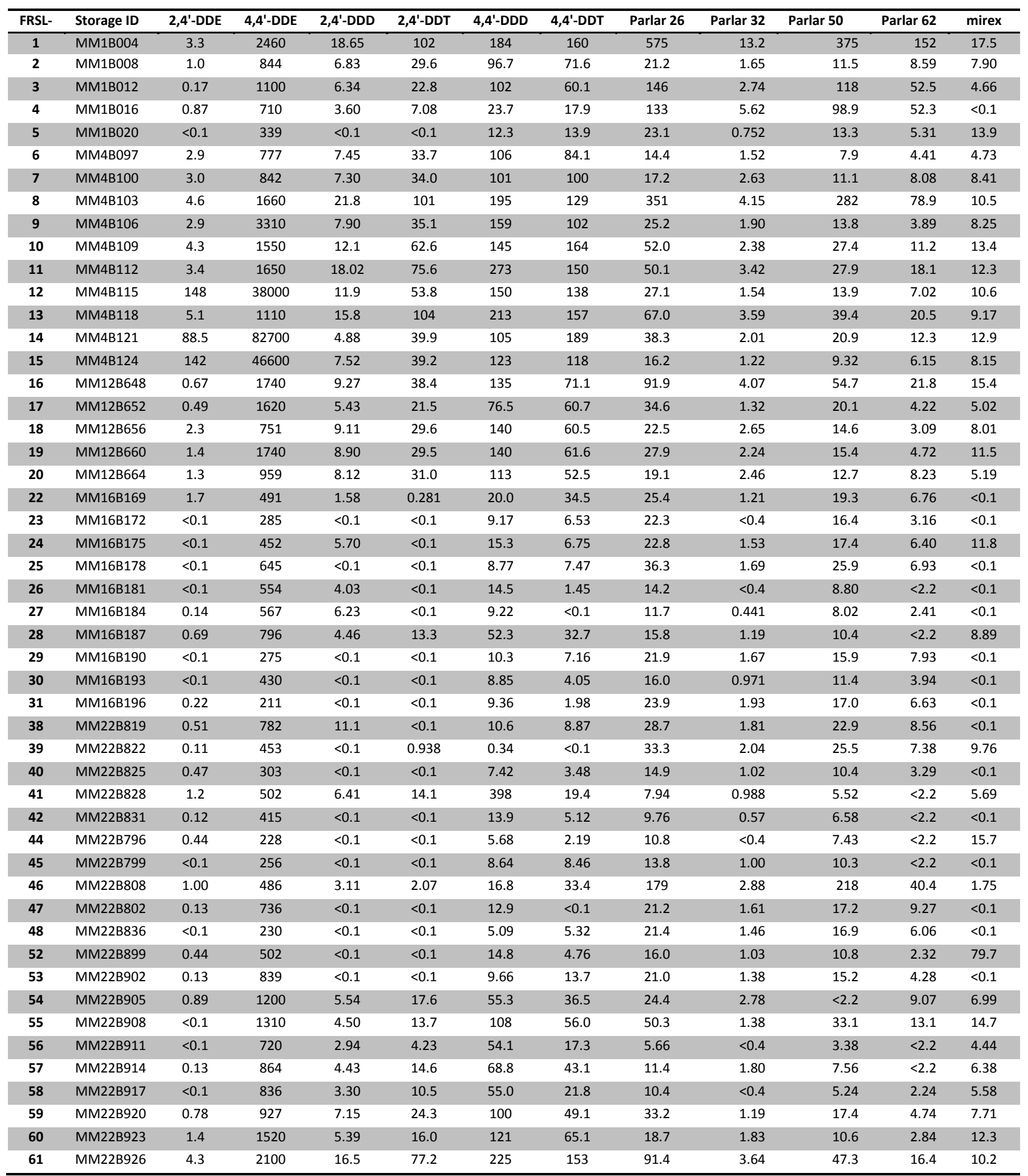


Table 11: Sums of the mass fractions of organohalogen compounds (ng/g wet mass) by group in northern fur seals.

\begin{tabular}{|c|c|c|c|c|c|c|c|c|c|c|}
\hline FRSL- & $\Sigma \mathrm{PCB}$ & $\Sigma$ DDT & $\Sigma$ Chlor & $\Sigma$ Tox & $\Sigma \mathrm{HCH}$ & $\Sigma \mathrm{ClBz}$ & Mirex & $\Sigma$ PBDE & $\alpha-\mathrm{HBCD}$ & $\Sigma$ PFAAs \\
\hline 1 & 1870 & 2920 & 1390 & 1120 & 333 & 3.3 & 17.5 & 7.3 & 2.6 & 6.9 \\
\hline 2 & 848 & 1050 & 404 & 42.9 & 263 & 6.2 & 7.9 & 1.5 & $<0.10$ & 8.1 \\
\hline 3 & 935 & 1291 & 514 & 319 & 284 & 7.5 & 4.7 & 1.0 & 0.15 & 26.3 \\
\hline 4 & 1800 & 763 & 732 & 290 & 554 & 5.2 & $<0.1$ & 6.5 & 0.36 & 27.1 \\
\hline 5 & 1100 & 366 & 472 & 42.4 & 339 & 3.9 & 13.9 & 2.7 & $<0.10$ & no value \\
\hline 6 & 996 & 1010 & 405 & 28.3 & 212 & 5.6 & 4.7 & 10.8 & 0.55 & 8.6 \\
\hline 7 & 1260 & 1087 & 455 & 39.1 & 208 & 2.4 & 8.4 & 11.6 & 0.71 & 19.6 \\
\hline 8 & 1510 & 2110 & 1110 & 716 & 368 & 4.5 & 10.5 & 13.9 & 3.6 & 9.3 \\
\hline 9 & 1830 & 3620 & 830 & 44.8 & 353 & 5.3 & 8.3 & 25.1 & 0.21 & 15.9 \\
\hline 10 & 2010 & 1940 & 1030 & 93.0 & 288 & 2.4 & 13.4 & 11.0 & 0.57 & 22.3 \\
\hline 11 & 1690 & 2170 & 939 & 99.5 & 332 & 3.2 & 12.3 & 9.0 & 0.79 & 50.4 \\
\hline 12 & 1870 & 38500 & 839 & 49.6 & 298 & 4.0 & 10.6 & 12.3 & 0.83 & 19.6 \\
\hline 13 & 1510 & 1610 & 716 & 131 & 476 & 2.9 & 9.2 & 10.1 & 0.55 & 4.9 \\
\hline 14 & 2190 & 83200 & 962 & 73.4 & 203 & 7.4 & 12.9 & 16.7 & 0.29 & 12.1 \\
\hline 15 & 1890 & 47000 & 662 & 32.9 & 239 & 2.3 & 8.1 & 9.4 & 0.23 & 10.2 \\
\hline 16 & 1740 & 2000 & 1010 & 173 & 293 & 3.4 & 15.4 & 14.4 & 4.7 & 28.6 \\
\hline 17 & 1050 & 1790 & 471 & 60.3 & 191 & 2.0 & 5.0 & 25.7 & 2.2 & 18.6 \\
\hline 18 & 1080 & 992 & 466 & 42.8 & 325 & 2.9 & 8.0 & 7.4 & 1.9 & 22.9 \\
\hline 19 & 1360 & 1980 & 581 & 50.3 & 291 & 4.1 & 11.5 & 19.2 & 1.4 & 23.4 \\
\hline 20 & 980 & 1160 & 441 & 42.5 & 172 & 3.5 & 5.2 & 10.3 & 3.3 & 45.9 \\
\hline 22 & 1960 & 549 & 461 & 52.7 & 308 & 1.6 & $<0.1$ & 39.6 & 2.0 & 11.7 \\
\hline 23 & 1890 & 300 & 305 & 41.8 & 192 & 2.2 & $<0.1$ & 16.8 & 1.5 & 86.1 \\
\hline 24 & 1210 & 480 & 422 & 48.1 & 284 & 1.7 & 11.8 & 33.2 & 1.8 & 81.6 \\
\hline 25 & 2080 & 661 & 659 & 70.9 & 331 & 1.8 & $<0.1$ & 60.8 & 2.4 & 54.9 \\
\hline 26 & 1690 & 574 & 386 & 23.0 & 243 & 2.9 & $<0.1$ & 15.8 & 1.3 & 38.8 \\
\hline 27 & 1830 & 583 & 302 & 22.6 & 192 & 1.7 & $<0.1$ & 21.5 & 0.87 & 40.4 \\
\hline 28 & 709 & 899 & 285 & 27.4 & 149 & 2.6 & 8.9 & 18.0 & 1.6 & 31.5 \\
\hline 29 & 2210 & 293 & 639 & 47.4 & 506 & 1.5 & $<0.1$ & 35.0 & 1.4 & 25.4 \\
\hline 30 & 1310 & 443 & 347 & 32.3 & 231 & 3.6 & $<0.1$ & 32.3 & 1.5 & 16.6 \\
\hline 31 & 1500 & 223 & 385 & 49.5 & 237 & 2.1 & $<0.1$ & 18.8 & 1.9 & 31.4 \\
\hline 38 & 1600 & 813 & 488 & 62.0 & 115 & 2.3 & $<0.1$ & 38.5 & 5.5 & 59.5 \\
\hline 39 & 1140 & 454 & 398 & 68.2 & 148 & 1.4 & 9.8 & 57.4 & 4.3 & 154 \\
\hline 40 & 1710 & 314 & 262 & 29.6 & 161 & 3.2 & $<0.1$ & 49.2 & 1.7 & 47.9 \\
\hline 41 & 558 & 583 & 181 & 14.4 & 231 & 4.3 & 5.7 & 10.0 & 1.6 & 162 \\
\hline 42 & 1920 & 434 & 260 & 16.9 & 125 & 3.3 & $<0.1$ & 39.8 & 1.2 & 37.0 \\
\hline 44 & 1340 & 237 & 265 & 18.2 & 149 & 2.8 & 15.7 & 14.9 & 1.7 & 20.6 \\
\hline 45 & 2040 & 273 & 266 & 25.1 & 155 & 2.8 & $<0.1$ & 20.1 & 1.8 & 164 \\
\hline 46 & 2080 & 543 & 775 & 440 & 125 & 1.7 & 1.8 & 93.2 & 22.4 & 41.9 \\
\hline 47 & 1560 & 749 & 457 & 49.3 & 205 & 3.4 & $<0.1$ & 55.7 & 3.7 & 47.2 \\
\hline 48 & 1390 & 240 & 191 & 45.8 & 103 & 2.3 & $<0.1$ & 28.9 & 2.2 & 30.3 \\
\hline 52 & 1590 & 522 & 436 & 30.2 & 229 & 6.3 & 79.7 & 60.6 & 2.7 & 137 \\
\hline 53 & 1690 & 863 & 590 & 41.8 & 254 & 3.1 & $<0.1$ & 97.8 & 5.2 & 44.9 \\
\hline 54 & 1090 & 1320 & 388 & 36.3 & 143 & 3.1 & 7.0 & 36.1 & 5.8 & 50.7 \\
\hline 55 & 1490 & 1490 & 733 & 97.9 & 257 & 5.4 & 14.7 & 15.4 & 7.7 & 37.8 \\
\hline 56 & 701 & 798 & 208 & 9.0 & 67 & 2.0 & 4.4 & 23.9 & 1.1 & 105 \\
\hline 57 & 843 & 995 & 314 & 20.7 & 108 & 2.9 & 6.4 & 23.8 & 4.2 & 42.7 \\
\hline 58 & 872 & 927 & 267 & 17.9 & 108 & 2.0 & 5.6 & 12.1 & 1.9 & 111 \\
\hline 59 & 1070 & 1110 & 409 & 56.5 & 121 & 2.0 & 7.7 & 28.3 & 5.2 & 89.3 \\
\hline 60 & 1690 & 1730 & 634 & 34.0 & 253 & 2.9 & 12.3 & 38.9 & 2.7 & 54.2 \\
\hline 61 & 1840 & 2580 & 853 & 159 & 254 & 3.6 & 10.2 & 49.2 & 10.0 & 99.2 \\
\hline
\end{tabular}


Table 12: Summary of organohalogen mass fractions ( $\mathrm{ng} / \mathrm{g}$ wet mass) determined in northern fur seals.

\begin{tabular}{lcccccccccc}
\hline & $\Sigma$ PCB & $\Sigma$ DDT & $\Sigma$ Chlor & $\Sigma$ HCH & $\Sigma$ Tox & Mirex & $\Sigma$ ClBz & $\Sigma$ PBDE & $\alpha-H B C D$ & $\Sigma$ PFAAs \\
\hline mean & 1480 & 4370 & 540 & 240 & 103 & 11.4 & 3.29 & 26.2 & 2.78 & 47.7 \\
geomean & 1410 & 1060 & 481 & 219 & 54.1 & 9.09 & 3.00 & 18.7 & 1.71 & 33.7 \\
median & 1540 & 913 & 459 & 234 & 45.3 & 9.03 & 2.93 & 19.0 & 1.82 & 37.0 \\
SD & 437 & 14100 & 270 & 103 & 190 & 12.6 & 1.49 & 21.3 & 3.53 & 41.4 \\
min & 558 & 223 & 181 & 66.7 & 9.04 & 1.75 & 1.37 & 1.03 & 0.15 & 4.86 \\
max & 2210 & 83200 & 1390 & 554 & 1120 & 79.7 & 7.54 & 97.8 & 22.4 & 164 \\
\#>LOD & $50 / 50$ & $50 / 50$ & $50 / 50$ & $50 / 50$ & $50 / 50$ & $34 / 50$ & $50 / 50$ & $50 / 50$ & $48 / 50$ & $49 / 49$ \\
\hline
\end{tabular}


Table 13: Mass fractions (ng/g wet mass) of PFAAs determined in the fish reference materials

\begin{tabular}{|l|c|c|l|l|l|l|l|l|}
\hline \multirow{2}{*}{ Compound } & \multicolumn{2}{|c|}{ SRM 1946 } & \multirow{2}{*}{ mean } & Certified Value & \multicolumn{2}{|c|}{ SRM 1947 } & \multirow{2}{*}{ mean } & \multirow{2}{*}{ Certified Value } \\
\cline { 2 - 3 } & Set 1 & Set 2 & & & Set 1 & Set 2 & & \\
\hline PFBA & $<0.9$ & $<6.3$ & & & $<0.8$ & $<8.2$ & & \\
\hline PFPeA & $<1.1$ & $<1.8$ & & & $<1.0$ & $<2.3$ & & \\
\hline PFHxA & $<0.1$ & $<0.9$ & & & $<0.1$ & $<1.2$ & & \\
\hline PFHpA & $<1.8$ & $<0.7$ & & & $<1.5$ & $<1.0$ & & \\
\hline PFOA & $<0.5$ & $<1.8$ & & & $<0.4$ & $<2.3$ & & \\
\hline PFNA & $<0.7$ & $<0.4$ & & & $<0.6$ & $<0.5$ & & \\
\hline PFDA & $<0.4$ & $<1.5$ & & & $<0.3$ & $<1.9$ & & \\
\hline PFUnA & $<1.5$ & 0.78 & & & $<1.3$ & $<0.74$ & & \\
\hline PFDoA & $<0.2$ & $<0.6$ & & & $<0.2$ & $<0.8$ & & \\
\hline PFTriA & $<0.2$ & 0.37 & & & $<0.1$ & $<0.3$ & & \\
\hline PFTA & $<0.3$ & $<0.4$ & & & $<0.3$ & $<0.6$ & & \\
\hline PFBS & $<0.1$ & $<0.2$ & & & $<0.1$ & $<0.3$ & & \\
\hline PFHxS & $<0.1$ & 0.12 & & & $<0.1$ & 0.16 & & \\
\hline PFOS & 1.84 & 2.29 & 2.07 & $2.19 \pm 0.08$ & 6.88 & 5.42 & 6.15 & $5.9 \pm 0.39$ \\
\hline PFOSA & $<0.1$ & 0.11 & & & $<0.1$ & $<0.1$ & & \\
\hline
\end{tabular}


Table 14: Mass fractions of brominated flame retardants ( $\mathrm{ng} / \mathrm{g}$ wet mass) in northern fur seal blubber

\begin{tabular}{|c|c|c|c|c|c|c|c|c|}
\hline FRSL- & Storage ID & BDE 47 & BDE 100 & BDE 99 & BDE 155 & BDE 154 & BDE 153 & $\alpha-H B C D$ \\
\hline 1 & MM1B004 & 2.7 & 0.70 & 0.65 & 0.45 & 2.5 & 0.34 & 2.64 \\
\hline 2 & MM1B008 & 1.0 & 0.47 & $<0.100$ & $<0.4$ & $<0.1$ & $<0.2$ & $<0.1$ \\
\hline 3 & MM1B012 & 1.0 & $<0.2$ & $<0.100$ & $<0.4$ & $<0.1$ & $<0.2$ & 0.15 \\
\hline 4 & MM1B016 & 2.8 & 0.63 & 0.72 & $<0.4$ & 1.8 & 0.52 & 0.36 \\
\hline 5 & MM1B020 & 1.5 & 0.25 & 0.26 & $<0.4$ & 0.65 & $<0.2$ & $<0.068$ \\
\hline 6 & MM4B097 & 8.0 & 1.05 & 0.86 & $<0.4$ & 0.60 & 0.29 & 0.55 \\
\hline 7 & MM4B100 & 7.3 & 1.1 & 0.92 & 0.60 & 0.90 & 0.83 & 0.71 \\
\hline 8 & MM4B103 & 6.2 & 2.7 & 1.1 & 0.48 & 2.6 & 0.85 & 3.5 \\
\hline 9 & MM4B106 & 12.3 & 3.6 & 4.2 & 0.53 & 2.8 & 1.6 & 0.21 \\
\hline 10 & MM4B109 & 7.4 & 0.92 & 0.99 & 0.47 & 0.87 & 0.33 & 0.57 \\
\hline 11 & MM4B112 & 4.9 & 1.6 & 1.0 & $<0.4$ & 1.2 & 0.35 & 0.79 \\
\hline 12 & MM4B115 & 8.3 & 1.3 & 0.76 & 0.48 & 1.0 & 0.43 & 0.83 \\
\hline 13 & MM4B118 & 5.6 & 1.8 & 0.97 & 0.42 & 0.95 & 0.38 & 0.55 \\
\hline 14 & MM4B121 & 9.0 & 1.1 & 1.2 & 0.61 & 3.3 & 1.5 & 0.29 \\
\hline 15 & MM4B124 & 5.8 & 1.1 & 0.99 & $<0.4$ & 0.78 & 0.77 & 0.23 \\
\hline 16 & MM12B648 & 7.2 & 2.3 & 1.6 & 1.09 & 1.7 & 0.65 & 4.7 \\
\hline 17 & MM12B652 & 16.7 & 3.1 & 3.5 & 0.43 & 1.4 & 0.48 & 2.0 \\
\hline 18 & MM12B656 & 5.4 & 1.5 & $<0.1$ & 0.44 & 0.18 & $<0.2$ & 1.9 \\
\hline 19 & MM12B660 & 9.8 & 3.4 & 2.2 & 0.63 & 2.0 & 1.2 & 1.4 \\
\hline 20 & MM12B664 & 6.1 & 1.6 & 1.4 & 0.43 & 0.51 & 0.21 & 3.3 \\
\hline 22 & MM16B169 & 24.3 & 6.7 & 4.7 & 0.59 & 1.8 & 1.4 & 2.0 \\
\hline 23 & MM16B172 & 10.8 & 2.4 & 2.4 & $<0.4$ & 1.2 & $<0.2$ & 1.5 \\
\hline 24 & MM16B175 & 21.5 & 3.8 & 5.2 & 0.45 & 1.3 & 0.85 & 1.8 \\
\hline 25 & MM16B178 & 40.2 & 3.3 & 8.7 & 1.01 & 3.3 & 4.2 & 2.4 \\
\hline 26 & MM16B181 & 7.6 & 2.4 & 2.0 & 0.48 & 1.8 & 1.5 & 1.3 \\
\hline 27 & MM16B184 & 11.9 & 2.6 & 3.6 & 0.57 & 1.5 & 1.3 & 0.87 \\
\hline 28 & MM16B187 & 12.1 & 3.0 & 1.9 & $<0.4$ & 1.0 & $<0.2$ & 1.6 \\
\hline 29 & MM16B190 & 24.0 & 3.8 & 4.5 & 0.45 & 1.5 & 0.86 & 1.4 \\
\hline 30 & MM16B193 & 19.3 & 4.3 & 5.0 & 0.57 & 1.9 & 1.3 & 1.5 \\
\hline 31 & MM16B196 & 10.8 & 2.3 & 3.5 & $<0.4$ & 1.3 & 0.86 & 1.9 \\
\hline 38 & MM22B819 & 24.2 & 4.0 & 5.3 & 1.0 & 2.4 & 1.5 & 5.5 \\
\hline 39 & MM22B822 & 37.8 & 7.5 & 6.7 & 0.94 & 2.5 & 1.8 & 4.3 \\
\hline 40 & MM22B825 & 30.4 & 8.3 & 6.4 & 0.62 & 1.9 & 1.7 & 1.6 \\
\hline 41 & MM22B828 & 5.9 & 1.4 & 1.4 & $<0.4$ & 0.71 & 0.71 & 1.6 \\
\hline 42 & MM22B831 & 25.8 & 5.0 & 6.0 & $<0.4$ & 1.3 & 1.7 & 1.2 \\
\hline 44 & MM22B796 & 9.9 & 1.1 & 2.3 & $<0.4$ & 0.81 & 0.77 & 1.7 \\
\hline 45 & MM22B799 & 11.8 & 4.3 & 2.0 & 0.50 & 0.83 & 0.70 & 1.71 \\
\hline 46 & MM22B808 & 57.8 & 18.3 & 10.2 & 1.2 & 3.9 & 1.7 & 21.7 \\
\hline 47 & MM22B802 & 31.4 & 8.0 & 9.4 & 1.0 & 2.9 & 2.9 & 3.6 \\
\hline 48 & MM22B836 & 18.7 & 4.8 & 2.7 & 0.51 & 1.4 & 0.75 & 2.1 \\
\hline 52 & MM22B899 & 38.2 & 9.0 & 7.7 & 0.94 & 2.5 & 2.1 & 2.7 \\
\hline 53 & MM22B902 & 60.3 & 19.1 & 8.7 & 1.6 & 3.9 & 4.2 & 5.1 \\
\hline 54 & MM22B905 & 27.5 & 3.1 & 2.6 & 0.82 & 1.3 & 0.76 & 5.8 \\
\hline 55 & MM22B908 & 9.1 & 2.4 & 1.2 & 0.91 & 1.2 & 0.54 & 7.7 \\
\hline 56 & MM22B911 & 13.8 & 5.3 & 2.8 & 0.52 & 0.87 & 0.62 & 1.1 \\
\hline 57 & MM22B914 & 14.6 & 3.1 & 2.8 & 0.84 & 1.4 & 0.98 & 4.2 \\
\hline 58 & MM22B917 & 5.6 & 2.7 & 2.1 & $<0.4$ & 0.86 & 0.90 & 1.9 \\
\hline 59 & MM22B920 & 16.6 & 5.7 & 3.2 & 0.52 & 1.5 & 0.78 & 5.2 \\
\hline 60 & MM22B923 & 26.8 & 4.8 & 4.7 & 0.65 & 1.2 & 0.68 & 2.7 \\
\hline 61 & MM22B926 & 31.5 & 9.2 & 3.6 & 1.2 & 3.0 & 0.77 & 9.9 \\
\hline
\end{tabular}




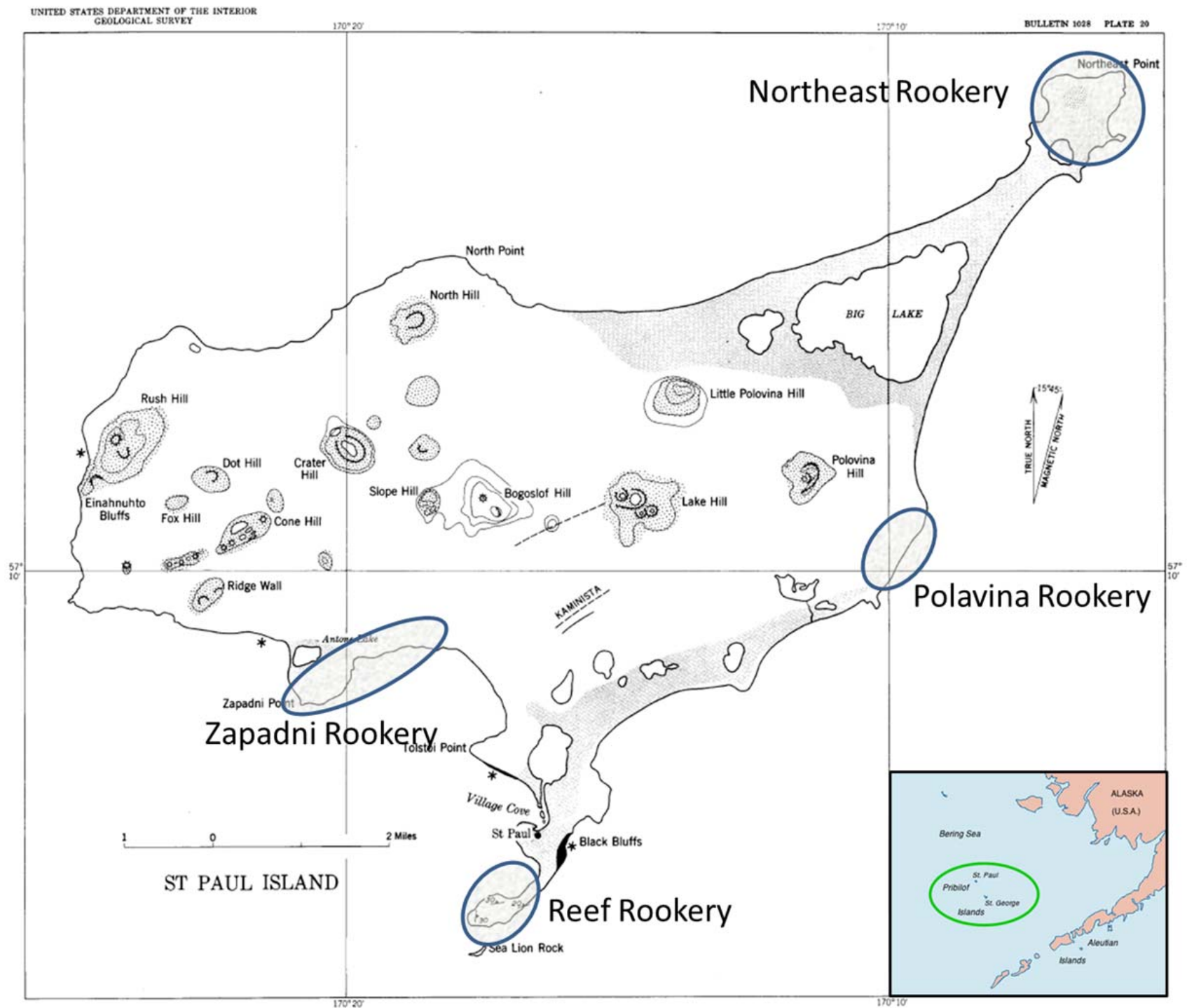

Figure 1: St. Paul Island and rookery locations 

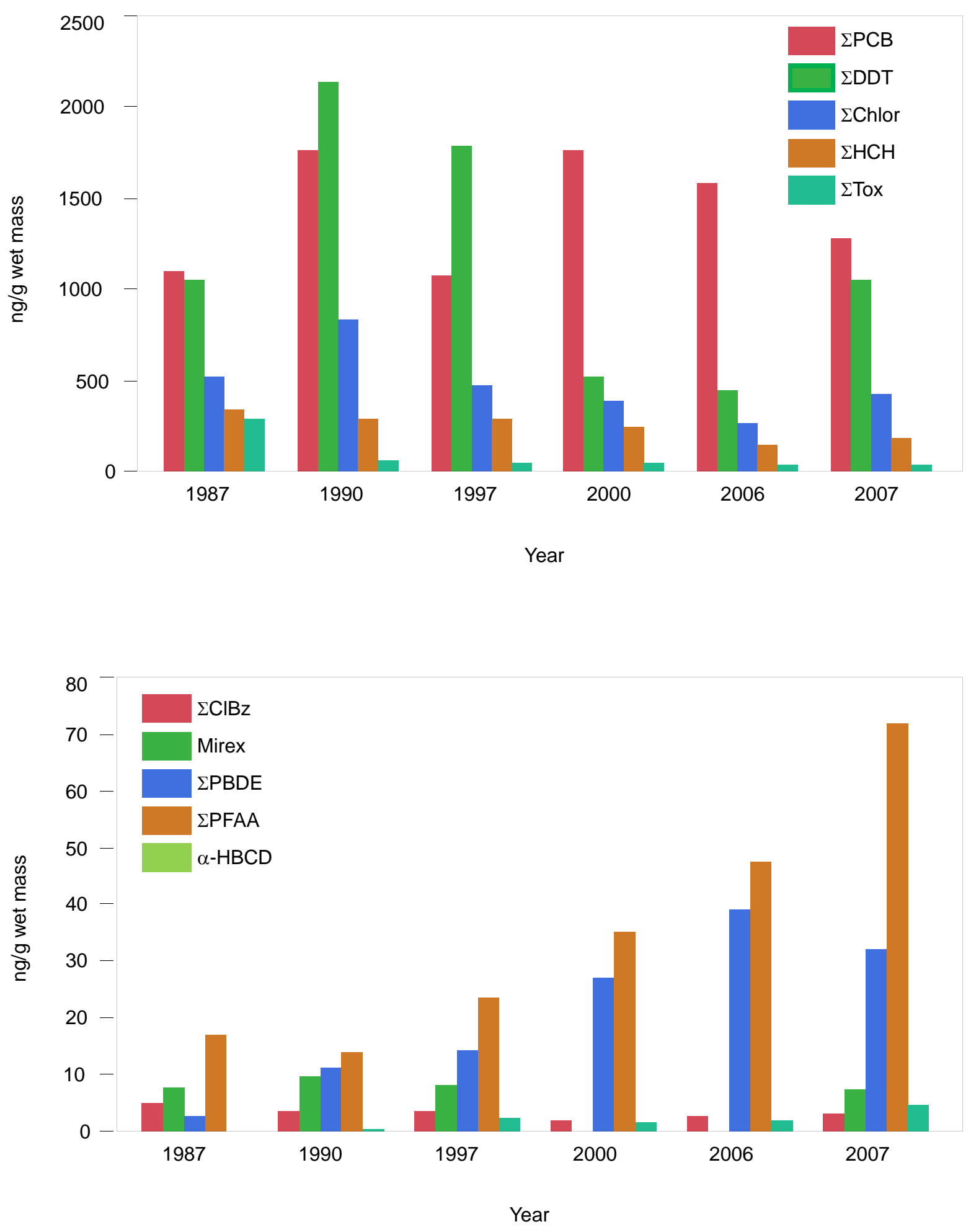

Figure 2: Median mass fractions of organohalogens in fur seals by year 

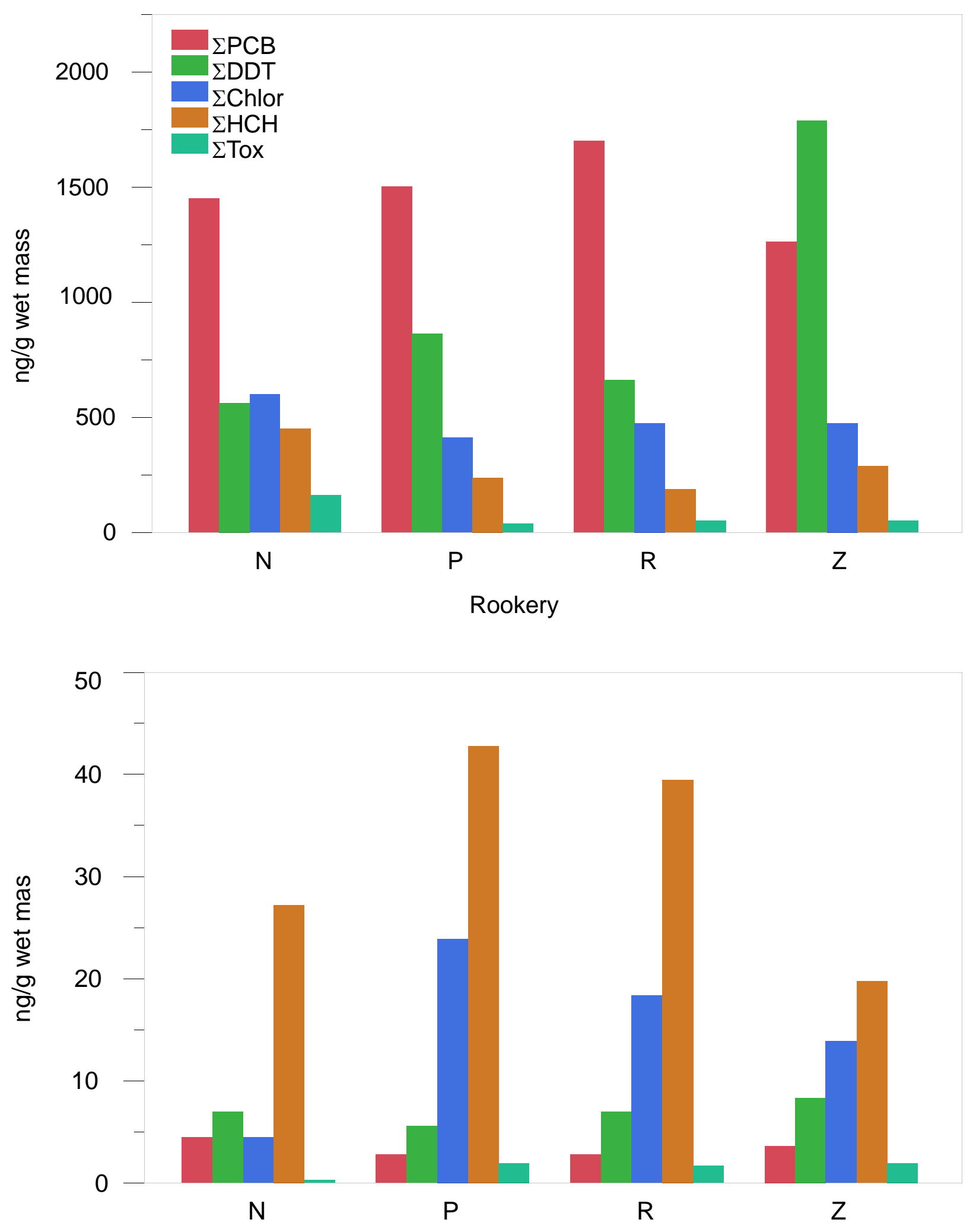

Figure 3: Median POP mass fractions by rookery (see Table 2 for number of seals per rookery). Rookery designations are Northeast (N), Polavina (P), Reef (R), and Zapadni (Z; See Fig. 1) 


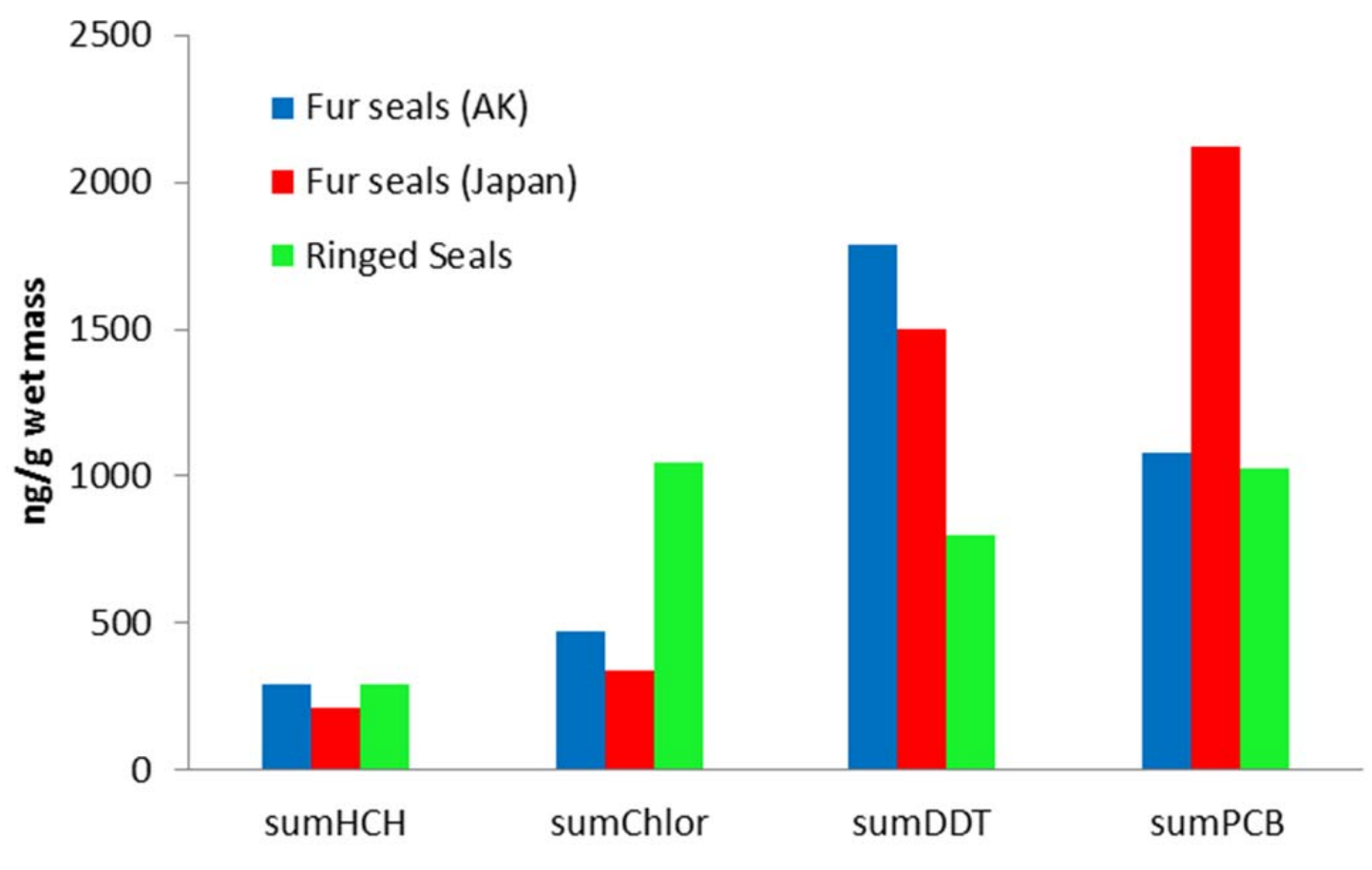

Figure 4: Mass fractions of legacy POPs in the current study (juvenile males) compared to NFS from the waters off of Japan and ringed seals from Norton Sound, AK. 